Sharif University of Technology
Scientia Iranica
Transactions E: Industrial Engineering
hCIENTIA

\title{
Benders decomposition algorithm for robust aggregate production planning considering pricing decisions in competitive environment: A case study
}

\author{
A. Aazami and M. Saidi-Mehrabad* \\ Department of Industrial Engineering, Iran University of Science and Technology, University Ave., Narmak, Tehran, P.O. Box \\ 1684613114 , Iran.
}

Received 13 November 2017; received in revised form 12 September 2018; accepted 13 October 2018

\author{
KEYWORDS \\ Bi-level aggregate \\ production planning; \\ Robust optimization; \\ Competitive \\ condition; \\ Pricing; \\ Benders \\ decomposition.
}

\begin{abstract}
In operations research, bi-level programming is a mathematical modeling which has another optimization problem as a constraint. In the present research, regarding the current intense competition among large manufacturing companies for achieving a greater market share, a bi-level robust optimization model is developed as a leader-follower problem using Stackelberg game in the field of Aggregate Production Planning (APP). The leader company with higher influence intended to produce new products, which could replace the existing products. The follower companies, as rivals, were also seeking more sales, but they did not have the intention and ability to produce such new products. The price of the new products was determined by the presented elasticity relations between uncertain demand and price. After linearization, using the KKT conditions, the bi-level robust model was transformed into an ordinary uni-level model. Due to the NP-hard nature of the problem, Benders Decomposition Algorithm (BDA) was proposed for overcoming the computational complexities in large scale. Finally, using the real data of Sarvestan Sepahan Co as a leader company, the validity of the developed model as well as efficiency and convergence of the BDA was investigated. The computational results clearly showed the efficiency and effectiveness of the proposed BDA.
\end{abstract}

(C) 2019 Sharif University of Technology. All rights reserved.

\section{Introduction}

Today, globalization of economy, rapid changes in technology, and different behaviors of the customers looking for more suitable and cheaper products have led to fundamental changes in the nature of market competition $[1,2]$. These factors, along with the advent of e-commerce, have resulted in a competition among large manufacturing companies for achieving a greater

\footnotetext{
*. Corresponding author. Tel./Fax: +9821 73225025 E-mail addresses: a_aazami@ind.iust.ac.ir (A. Aazami); mehrabad@iust.ac.ir (M.Saidi-Mehrabad)
}

market share [1-5]. As an example of such competition, two hardware manufacturers, namely HTC and Nokia, are competing for more sales in the market [1]. In such a situation, some questions may come to mind such as "which company will win the competition?" and "what market share will be achieved by the winner company [6]?" The present study aims to answer such questions and simply model the competition between a manufacturing company, which has a higher selling power and popularity in market as a leader, and others. It is of a great importance and revenue to the leader to consider the competition in its APP and pricing decisions as a bi-level model.

As one of the most important problems in production systems, especially in current competitive mar- 
kets, production planning aims at coordinating the production activities and providing an effective plan that optimizes objectives of the companies. In fact, production planning is a decision-making process of allocating resources to the production activities in a cost-effective manner that makes it possible for the manufacturer to be the winner of the competitive market [7]. APP, as a special production planning, comprises the simultaneous determination of production, inventory, and employment levels as well as other important production variables of a company during a finite planning horizon. Usually, the planning horizon of APP ranges from 6 months to one year. Assuming the production capacity constraint, the objective of the APP is normally to minimize the total costs while meeting the non-constant and fluctuating demand [8].

In the present research, the main competition is between the leader company, with a higher selling power and popularity, and the follower companies. These companies are independent and seek a greater market share. In fact, the competition is on the amount of sales and price of products. It should be noted that in the developed model, the focus is on the leader in that its decisions affect the decisions of the followers due to its higher popularity. This type of competition is modeled using a Bi-level Linear Programming (BLP) [9]. After linearization, using the KKT conditions, the bi-level APP model is transformed into an ordinary uni-level one. By solving the developed model, in addition to the APP decisions and the amounts of sales of the leader and the follower, the price of products is determined using elasticity relations.

Compared to the existing literature, the main contributions of the present study can be enumerated in 3 aspects. The first one is that we consider the competition between a manufacturer company with its corresponding Supply Chain (SC) and other manufacturer companies with their corresponding SCs in a competitive market. The main competitive factor is the selling price, which is determined using the proposed elasticity relations between the demand and price under pricing decisions. We utilize a leader-follower bi-level programming approach using the concept of Stackelberg game for developing the competitive APP model. To the best of our knowledge, there is no modelling effort that considers this kind of competition in the APP problems. The second one is that we address the inherent uncertainty of the parameters of the problem, especially market demand, which is controlled using multiple scenarios. In fact, we solve the uncertainty using a robust optimization method introduced by Mulvey et al. [10], which has not been used by researchers in the literature for the competitive APP problem. Considering the inherent uncertainty makes the modeling of problems much closer to the real conditions. According to the research of Makui et al. [7], the APP problems are among the strongly NPhard ones and the use of meta-heuristic methods for solving such problems would not guarantee obtaining accurate and global optimal solutions. Consequently, it can be claimed that the developed model is NPhard and an efficient algorithm is needed to overcome its computational complexity. Therefore, as the third contribution, the powerful Benders Decomposition Algorithm (BDA) is proposed to solve the developed NPhard model in large scale. We also study a real-life case from Sarvestan Sepahan Co., as a leader in the competitive market, in order to indicate applicability of the developed model and BDA to the real-world cases of APP.

The rest of the paper is organized as follows. Section 2 provides a review of the literature on APP, production planning, and the BLP problem in competitive market environment as well as the pricing problem. In Section 3, the mathematical model of bi-level APP in competitive environment is developed in the presence of uncertainty. Section 4 presents the proposed BDA for solving the developed model in large dimensions. In Section 5, performance and efficiency of the developed model are tested using a set of data of a school notebook manufacturing company in Isfahan, Sarvestan Sepahan Co. Finally, the last section provides conclusion as well as some suggestions for future studies.

\section{Literature review}

The intense competition in competitive market has compelled the companies to satisfy the demand of customers with high speed and quality [11]. In most of the recent optimization and simulation models, it has been attempted to consider the existing competition in the market. Thus, it is very important to model the competition and solve the pricing problem to meet the demand. This section reviews the previous studies of modeling of the competitive environment for manufacturing companies (particularly the bi-level models) as well as the studies of the product pricing problems. Once a manufacturing company has no rival in the market, it will indeed be an exclusive company that obtains the whole market share. However, since there are other rivals in the market, in many cases, exclusiveness of the manufacturing company will be an unreal assumption [12].

Review of the literature is presented in the following two sub-sections. First, the studies of BLP and pricing problems in a competitive market environment are presented. Then, some of the most important researches in the field of production planning as well as APP will be reviewed. 


\subsection{Review of the literature on bi-level programming and pricing problems}

In this section, we review a large and growing bodyof literature in the field of BLP modeling with focus on the application of the BLP approach to formulating some problems such as Supply Chain Network Design (SCND), production planning, transportation, pricing, location-allocation, etc. According to our investigations, the main modeling of the BLP was presented for the first time in a study conducted by Bracken and McGill [13] in 1973, while, later, Candler and Norton [14] were the first ones who used the name of bi-level and multi-level programming. Such problems did not attract attention of the researchers up to about 8 years later. Several researchers investigated the BLP with regard to the theory of Stackelberg game [15] and developed its mathematical formulation [16]. For further studies in this field, the interested readers can refer to the highly valuable information in [14,16-24].

Ben-Ayed et al. [25], as the first researchers, modeled the network design problem in the form of the BLP. They considered both the convex and concave investment functions in their formulation. Bard and Moore [26], who were pioneers in the field of the BLP, presented the branch and bound algorithm for solving the quadratic BLP. Continuing their research, they [27] introduced a new algorithm for the discrete BLP, which began by transforming the objective function of the leader into a parametric constraint. Edmunds and Bard [28] developed an algorithm based on the branch and bound for Bi-level Non-Linear Programming (BNLP) problem. They helped completing the literature in this regard and their paper was among the first studies of the BNLP. Yang [29] applied the BLP approach to the origin-destination matrix estimation problem in congested networks and presented efficient heuristic algorithms. Their approach integrated the standard least squares model and the standard network equilibrium model into one process. In 1998, Bard [23] presented optimization of the BLP problem along with all of its algorithms and applications in a book, which has been a scientific reference for the BLP problems.

Most of the previous reviewed papers were published before 2000. In the following, the literature after 2000 will be investigated. Maher et al. [30] formulated two problems in transportation network including trip matrix estimation and traffic signal optimization applying the BLP approach with stochastic equilibrium link for users. They proposed a solution algorithm for the two BLP problems and examined their algorithm on some networks. Moreover, Burgard et al. [31] applied the BLP modeling to chemical problems to identify gene knockout strategies for optimizing microbial strain. Gao et al. [32] developed a traditional BLP model for discrete network design problem and proposed a new solution algorithm using support function concept to represent the relationship between improvement flows and new additional links. Shi et al. [33] contributed a generalized branch and bound algorithm to the literature for solving the BLP problems. The branch and bound algorithm has been the most successful algorithm for the BLP to overcome the complementary constraints resulting from the KKT conditions.

According to our vast searches, the first serious studies on the competition between two SCs were presented by Zhang [3]. He presented a variation inequality model to the literature on competition, in which the winning $\mathrm{SC}$ and its market share were determined. In 2007, Colson et al. [22] published a review paper in which they investigated many papers on bi-level optimization from both theoretical and practical aspects and presented the existing gaps in this field. Sun et al. [34] developed a BLP model as well as a simple heuristic algorithm in order for the location of the logistics distribution centers to be determined. The upper level was to find the optimal location and the lower determined an equilibrium demand distribution. Saharidis and Lerapetritou [9] presented a new solution method for the BLP problems based on the decomposition technique. Their proposed algorithm was based on the decomposition of the primary problem into a restricted master problem and multiple sub-problems using the BDA. In the field of pricing and competition, Xiao and Yang [1] developed a competitive model of two SCs under demand uncertainty with price and service factors in order to assess the optimal decisions of chain components. Each SC included one riskneutral supplier and one risk-averse retailer. Zhang and Rushton [12] developed a multi-site location-allocation model to select locations in competitive service systems. Their presented objective function maximized utility of users with constraints on the waiting time of users and budget of owners. Zhang et al. [35] developed a BLP model for a seaport container transport network, in which the transportation companies competed on using the path with the lowest cost.

In the following, the related literature after 2010 will be reviewed. Gelareh et al. [36] designed a liner shipping hub network in a competitive environment and investigated the competition between a newcomer provider and an existing well-known operator. The newcomer maximized its market share by locating predetermined hubs in candidate ports and designing the network. Küçükaydin et al. [37] investigated the competitive facility location problem by determining the attractiveness of the follower. They formulated a BNLP model in which the leader was a new firm with a facility location problem to maximize its profit and the follower was its rival firm with existing facilities. Naimi Sadigh et al. [38] studied coordination of the manufacturer-retailer SC with price-dependent demand within Stackelberg game framework. They 
also utilized the BLP to find advertising expenditures, optimal equilibrium prices, and production policies. Kristianto et al. [39] presented a two-stage bi-level stochastic model for the mass production problem and considered the manufacturer as the leader and the consumer as the follower in order to model the contradictory objectives between them. They used the BDA to solve the proposed complex model and obtain an optimum solution.

In recent years, the number of studies in the literature on the application of the BLP approach by considering competition in SCs has been increasing. Rezapour and Zanjirani Farahani [40], as well-known researchers in the field of modeling of competition, developed a new stochastic BLP model to design a competitive SC considering the two competitive factors of price and service level with foresight. They assumed that the network of the new SC was set "once for all," but further price and service level modifications were possible. Rezapour et al. [41], in another research, used dynamic BLP to design an entrant SC for competition against an existing SC, where demand was elastic with respect to price and distance. They modeled the problem with the strategic facility location and flow decisions, and proposed exact and metaheuristic algorithms. Fallah et al. [6] considered the competition between two closed-loop SCs including manufacturers, retailers, and recyclers, in which the competition factors were the prices of new products and the incentives given to consumers for taking back the used products. They studied the impact of simultaneous and Stackelberg competitions between two closed-loop SCs on their profits, demands, and returns in a nondeterministic environment. As a more related study to the previous research, Rezapour et al. [42] developed a competitive closed-loop SC model using the BLP with price-dependent demands in order to design a strategic reverse network and tactical/operational planning. They considered competitions not only externally between two chains supplying new products but also internally in the new chain for supplying new and remanufactured products.

In more recent studies, Rashidi et al. [43] developed a BLP model for the location of crosswalks in a multimodal transportation network to minimize the pedestrians' safety hazard and total transportation cost. They employed a greedy heuristic and a simulated annealing algorithm to solve the problem. Han et al. [44] presented a solution to the bi-level and trilevel programming problems using Particle Swarm Optimization (PSO) algorithm. They first developed a novel bi-level PSO to solve general BLP problems and then, proposed a tri-level PSO for handling the tri-level programs that were more challenging than the BLPs. Saranwong and Likasiri [45] used the BLP to solve Distribution Center (DC) problem by which the upper- and lower-levels were to minimize the transportation cost of shipping products from plants to DCs and from DCs to customers, respectively. They also presented four algorithms to obtain an optimal trade-off between the objective function values of the two levels. In the last paper we reviewed, but certainly not the latest research conducted on the BLP, Shamekhi Amiri et al. [46] developed a BLP for two competitive SCs under foresight competition and variable coverage. They proposed an iterative global search approach that inserted, in each iteration, the reaction of the follower in the leader's problem as new constraints.

Although researchers have noticeably focused on using the BLP approach in formulating some problems in the competitive environment, the explored literature on the BLP reveals that, to the best of our knowledge, there is almost no modeling effort that develops a BLP for the APP problems, especially where a manufacturer company competes with other manufacturer companies in their SCs.

\subsection{Review of the literature on production planning and APP}

In this sub-section of literature review, we investigate some important papers published after 2000 in the field of production planning and APP. Ghazanfari and Murtagh [47] proposed a single-stage model for multiobjective hierarchical production planning problem with stochastic demand using chance-constrained goal programming approach. Their model had two levels, namely product type and product family, in which a type was a set of families with the same cost per unit of time. It is clear that the first level referred to the APP. In 2006, Mula et al. [48] reviewed the literature on production planning problems, especially under uncertainty conditions. Their review included 83 papers from 1983 to 2006. According to their investigations, considering uncertainty in manufacturing systems was a major progress, that is, the production planning models that ignored uncertainty had a very low rank relative to the models that included it. Leung and $\mathrm{Ng}$ [49] developed a three-objective goal programming model for the APP of perishable products. By applying postponement policy, they suggested dividing the production process of these products into two phases, including semi-finished production and final assembly. Leung and Chan [50] developed a goal programming model for the APP by considering the resource utilization constraints such as production and machinery capacities. The objective functions were to hierarchically maximize profit, minimize repairing cost, and maximize machine utilization of a Chinese production plant in comparison to two other American ones.

After 2010, Mirzapour Al-e-Hashem et al. [51] developed a multi-objective robust optimization model for a multi-product and multi-site $\mathrm{APP}$ in an SC 
including multiple suppliers, multiple manufacturers, and multiple customers. The first objective function minimized the total losses of $\mathrm{SC}$, such as production cost and hiring/firing cost, and the second objective function took customer satisfaction into account through minimizing the amount of shortages. Subsequently, Zhang et al. [52] developed a collaborative model for production planning in a multi-echelon SC under uncertain demand and price. They determined the production planning issue by considering bill of materials and the trade-offs between inventories, production costs, and customer service level. To solve the complex model, they combined the scatter evolutionary algorithm, fuzzy programming, and stochastic chanceconstrained programming. Ghasemi Yaghin et al. [53] presented a fuzzy goal programming for integrated pricing and APP in a two-echelon SC through a hybrid fuzzy multiple-objective approach. The objectives of their model were to maximize the total profit of manufacturer as well as the retailer and improve service aspects of retailing, simultaneously. Developing an APP model for two-phase production systems and solving it by genetic algorithm and Tabu search were studied by Ramezanian et al. [54]. Their considered objective function was to minimize costs and instabilities in the work force and inventory levels.

In recent 5 years, Awudu and Zhang [55] were among the researchers who conducted studies in this field. They presented a stochastic production planning model for a biofuel SC under uncertain demand and price to maximize profit. Their model determined the amounts of purchased raw materials, consumed raw materials, and produced products. They used the BDA with Monte Carlo simulation technique to solve the proposed model. Rahmani et al. [56] utilized a robust approach to formulating the APP problem in which some of the model parameters such as production costs and demand were fuzzy variables. They also used the concept of entropy to reduce the sensitivity of the fluctuating data and achieve a more robust APP. Da Silva and Marins [57] presented a fuzzy goal programming model for solving a real APP problem under uncertainty applied the case study of a sugar mill. The decisions of agricultural and logistics phases were made on a weekly planning horizon to contain the whole harvesting season and the periods between harvests. Chakrabortty et al. [58] conducted a research on the PSO based on a possibilistic environment for a multi-period and multi-product APP problem. They proposed an approach that used a triangular possibility distribution to handle all the imprecise operating costs, demands, and the data related to capacity. Jabbarzadeh et al. [59] developed an enhanced robust approach to the supply and demand management in simultaneous production-distribution planning under uncertainty. Their approach, called
"Elastic p-Robustness," resolved the need for estimating the probability distribution of uncertain parameters when managing operational uncertainties of SC. Using production postponement policy, Makui et al. [7] contributed the robust APP problem to the literature for products with a very limited expiration date. In fact, they developed the model proposed by Leung and $\mathrm{Ng}$ [49]. They also proposed an exact solution approach, known as accelerated BDA, with two efficient acceleration inequalities to solving their problem.

In more recent papers, Ramyar et al. [60] developed a multi-objective model for the APP in an $\mathrm{SC}$ with the objectives of minimizing the total cost and maximizing the minimum reliability of suppliers. They considered the probabilistic lead times in order to improve performance of the system and presented a Pareto-based multi-objective harmony search algorithm. Recently, Entezaminia et al. [61] proposed a robust multi-objective multi-site APP model in a green SC by considering the reverse logistics network. They took into account some green principles such as waste management, greenhouse gas emissions related to transportation modes, and production methods. Mokhtari and Hasani [62] presented a multi-objective fuzzy optimization model for cleaner productiontransportation planning problem in manufacturing plants. They specified the optimal production level, inventory level, workforce level, back order level, transportation mode, and subcontracted products and minimized production and transportation costs as well as environmental effects. As the last paper reviewed in the field of production planning, Hahn and Brandenburg [63] considered two relevant features of APP:

1. Sustainable operations planning including multiple alternative production modes with the particular carbon emission related to production and social dimensions of different operating rates;

2. Integrated campaign planning with the operational level in order to predict production decisions on lead times and work-in-process inventories. They considered carbon emission and overtime working hours as externalized factors and considered the internalized factors in terms of the resulting costs.

In the precise investigations and comprehensive review of the literature, it is observed that during the past 30 years, much more information has become available about the APP and the BLP, but so far no model has been developed using the leader-follower BLP using the concept of Stackelberg game in an APP with the outputs of production decisions and new product pricing, where pricing is done under elasticity relations between demand and price in a competitive market environment. In the present study, the inherent uncertainty of the problem parameters, 
especially market demand, is considered as a multiscenario state and controlled using the Mulvey et al. technique [10], which makes the modeling much closer to the real market conditions. Furthermore, due to NPhardness of the problem, the BDA has been proposed for dealing with the computational complexities of large dimensions. The BDA has considerable profits over other solution methods (such as heuristic and meta-heuristic methods) including:

1. This algorithm is based on powerful algebraic concepts;

2. Convergence of the algorithm and achieving optimal solution have been proved analytically;

3. Each decision-maker can set the optimality gaps, precisely.

In order to show applicability of the robust optimization model and the proposed solution approach, the real data of Sarvestan Sepahan Co., as the leader in competitive market, has been used. Therefore, in the next section, an existing model in APP is developed by applying fundamental and more realistic changes in the production problem as well as by considering the competition in production of the products as a bi-level model. Some of the efficient features of the proposed model are its simplicity and applicability to problems of the real world, especially the production problems of new products.

\section{Mathematical modeling}

\subsection{Problem description}

In the given problem, a leader company and several follower companies (rivals) are competing on the amount of sales and the selling price of products to acquire more revenue. The leader company, due to its background and higher popularity, has more power to acquire market share. The type of the competition in the market is pure, but the leader company is more known and older than its rivals. The main problem is that the leader company intends to produce some new products capable of replacing the existing products, while the rival companies do not intend and are not able to produce such new products. The amount of sales and the selling price of products for both the leader and the follower companies in addition to some variables related to the APP problem of the leader company should be appropriately determined. Because one manufacturer company has more power to acquire market share and act as a leader, the competition is modeled using BLP with regard to the concept of Stackelberg game [15], which properly matches the problem. Also, the basic APP model has been taken from the study by Makui et al. [7] and developed for the real competitive conditions. Figure 1 clearly illustrates the structure of the problem and the relationship between the leader and the follower in the competitive market.

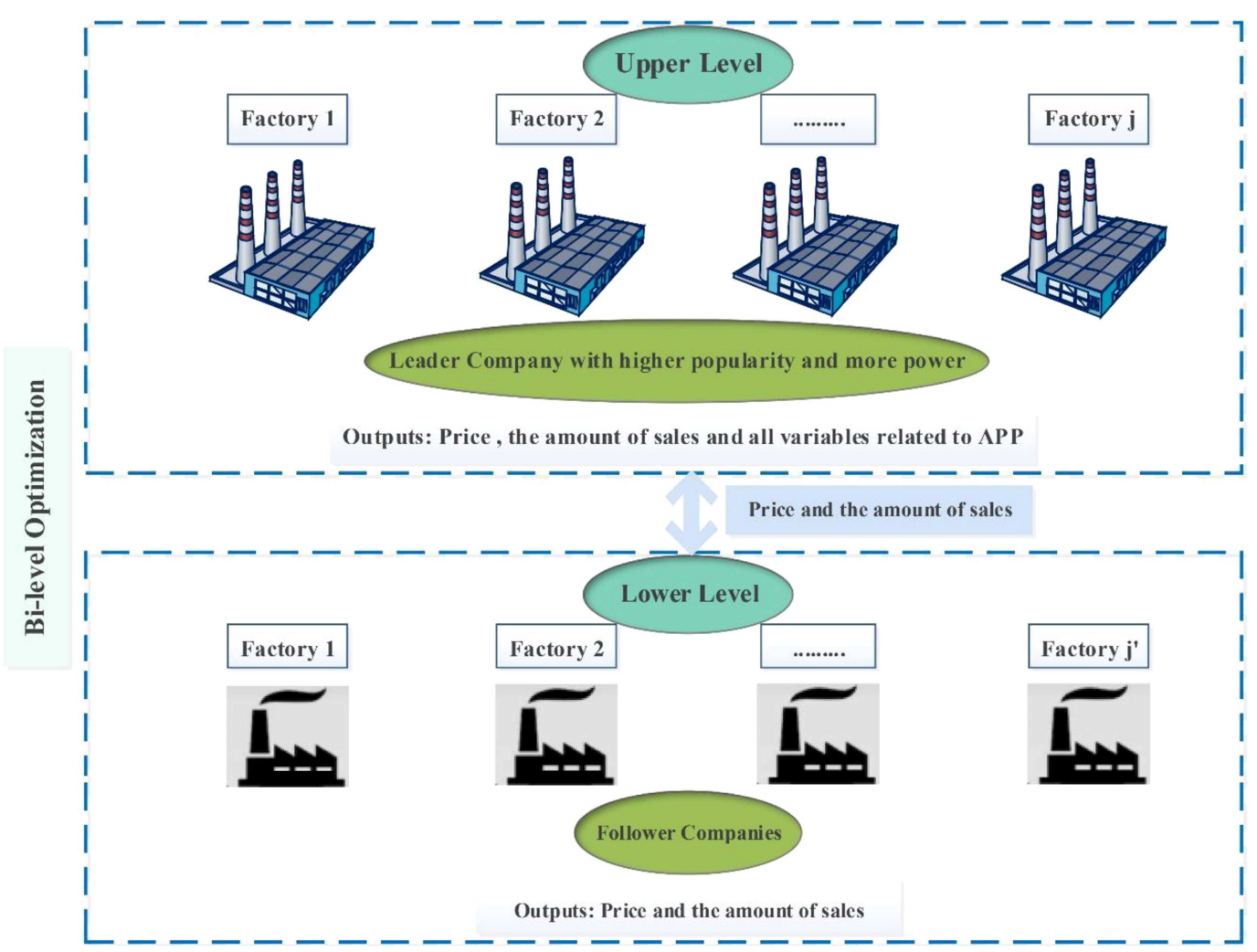

Figure 1. The structure of the competitive environment. 
This APP problem minimizes the costs to the leader company including production, setup, workforce, labor, inventory, hiring, and laying-off costs. Regarding the stochastic demand value, the model determines the production amount of product $i$ in the manufacturing factory $j$ by the workforce at level $k$ in period $t$. Furthermore, the proposed model specifies the selling price, product inventory, number of the workforce, numbers of hiring and laying-off, and the amount of product that exceeds the demand for any type of product (over-fulfilment or oversupply). Since the revenue of the leader is deducted from the cost, the objective function of the leader is to minimize the total loss. The production problem for the rival companies has not been modeled due to special attention to production problem of the leader and the lack of information about rival companies. Therefore, the objective function of the follower will merely be maximization of the sales revenue.

Considering the existing historical data and based on the comparison of the new products of the leader with similar products in the market, market demand along with some parameters of the APP is uncertain and they have inherently stochastic behavior in each period. This stochastic uncertainty can be a result of different factors such as change in the manner of customers and the existence of some complementary and alternative products. Thus, due to this uncertainty and because there is no information about their means and standard deviations to find their distributions, regarding the historical data and opinions of the experts, we only consider the states with the greatest probabilities instead of addressing all possible states of the uncertain parameters. It is clear that the states with the greatest probabilities are limited to some countable scenarios. Accordingly, some more probable scenarios with their probabilities of occurrence along with the value of each uncertain parameter in each scenario can be specified. The type of the considered uncertainty is a discrete stochastic variable of which the probability function is specified. Hence, scenario-based stochastic programming approach is the best approach to controlling and tackling this type of uncertainty. Finally, an extended version of this approach, known as the scenario-based robust stochastic programming, introduced by Mulvey et al. [10] is used. Using the scenario-based robust stochastic programming, the concepts of solution robustness and model robustness, which are illustrated in Section 5.3, can be integrated. It also should be noted that some basic studies have used this approach for the APP and they note that "as economic scenarios are taken into account, changes in uncertain data do not have significant effect on an optimized production planning" $[7,64]$. The interested readers can refer to references $[10,61,65-71]$ to obtain more information about the robust optimization ap- proach. In this paper, the amounts of production and inventory are considered as control variables.

The main assumptions of the model are as follows:

- The problem is multi-product and multi-period, and the location of each factory is fixed and predetermined;

- Each manufacturing factory is able to produce different types of products in each period;

- Production and inventory capacities of the leader and selling capacity of the follower are assumed to be limited;

- Fluctuating demand and some cost parameters are naturally uncertain and controlled by a multiscenario approach. The probability of each scenario is estimated using the historical data and opinions of the experts;

- The production of each product can be set up in each period;

- The leader company has more power to acquire market share due to its higher popularity;

- Although selling price is determined using the proposed elasticity relations between demand and price, it should be in a specified range;

- The elasticity relations between demand and price are linearly determined using the historical data and regression relations.

In our model, the following main decisions are determined under the competitive environment and uncertainty:

A) The main decisions of the leader include:

$\checkmark$ The selling price and the amount of sales of the final product;

$\checkmark$ The amount of production and inventory of final products;

$\checkmark$ The number of workforce, including hired and laid-off workforce.

B) The main decisions of the follower include:

$\checkmark$ The selling price and the amount of sales of the final product.

Subsequently, first, the elasticity relations between demand and price are determined in general state. Then, the mathematical model is presented.

\subsection{Presenting elasticity relations between demand and price in general state}

Assume that $d_{L}$ is the portion of the market demand which the leader $(L)$ potentially has and $P_{L}$ is the price quoted by the leader. Also, assume that $d_{F}$ is a portion of the market demand, which is potential for the follower $(F)$, and $P_{F}$ is the price quoted by the 
follower. Regarding these quoted prices, the demand to the leader $(L)$ and follower $(F)$ is determined by Eqs. (1) and (2); these demand-price equations are based on the economic theories in competitive markets in which a reverse relationship exists between price and demand [6]:

$$
\begin{aligned}
& d_{L}=\alpha_{L}-\beta_{L} \cdot P_{L}, \\
& d_{F}=\alpha_{F}-\beta_{F} \cdot P_{F} .
\end{aligned}
$$

In these equations, $\beta_{L}$ and $\beta_{F}$ are respectively the price elasticity of $L$ (leader) and $F$ (follower) to demand, indicating that with $1 \%$ increase in price, the demand level is reduced by a few percent $\left(\beta_{L}\right.$ and $\beta_{F}$ are both positive).

Also, $\alpha_{L}$ and $\alpha_{F}$ indicate the selling power of $L$ and $F$ in market, respectively:

$$
\begin{aligned}
& P_{L}=\frac{\alpha_{L}-d_{L}}{\beta_{L}}, \\
& P_{F}=\frac{\alpha_{F}-d_{F}}{\beta_{F}} .
\end{aligned}
$$

Obviously, assuming equality of $\beta_{L}$ and $\beta_{F}$, if $\alpha_{L}>\alpha_{F}$, then at the same demand level, the leader price can be higher according to Eq. (3). Parameter $\alpha$ can be derived from factors such as quality, popularity, service level, and advertisement; thus, its higher values are desirable because there will be more power for sales.

Considering the reverse relationship between demand and prices, if both sellers produce the same product and are rivals, then the customer will consider their prices, simultaneously. Therefore, in the leader equation (Eq. (1)), the price of $F$ and similarly, in the follower equation (Eq. (2)), the price of $L$ will be effective. According to Eq. (1), if $L$ increases its price, then the demand level for its products will be reduced. The same also holds for $F$ based on Eq. (2). Now, it is obvious that if the market price of the rival $(F)$ is reduced, then the demand level of $L$ will be reduced, and if the price of $F$ is increased, then the demand level of $L$ will be increased as well. Therefore, in a linear state, Eq. (5) can be proposed for developing Eq. (1) by considering the price of the rival $(F)$ [42]:

$$
d_{L}=\alpha_{L}-\beta_{L} \cdot P_{L}+\gamma_{L} \cdot P_{F} .
$$

Similarly, Eq. (6) is given for the follower $(F)$ :

$$
d_{F}=\alpha_{F}-\beta_{F} \cdot P_{F}+\gamma_{F} \cdot P_{L} .
$$

In Eq. (5), $\gamma_{L}$ is defined as the price elasticity of rivaldemand for $L$, which implies that a unit of increase in the price of $F$ will increase the demand to $L$ by $\% \gamma_{L}$.

\subsection{Modeling using the bi-level programming}

In this section, using the BLP, a mathematical model is developed which considers the competition between the leader and the follower. The output of this model will be the selling prices of the leader and the follower as well as the amount of sales of each one and the APP variables. The results obtained from the proposed model will be efficient for all the companies producing in the competitive market. In the following, the parameters and decision-making variables will be introduced and then, the defined problem will be modeled.

\subsection{Notations}

Indices:

$i \quad$ Index of products

$j \quad$ Index of factories of leader company

$j^{\prime} \quad$ Index of factories of rival companies

$k \quad$ Index of workforce levels

$s \quad$ Index of uncertainty scenarios

$t \quad$ Index of time periods

\section{Parameters:}

$\alpha_{i j t} \quad$ Leader's power to sell product $i$ produced by factory $j$ at period $t$

$\alpha_{i j^{\prime} t}^{\prime} \quad$ Follower's power to sell product $i$ produced by factory $j^{\prime}$ at period $t$

$\beta_{i j t} \quad$ Price elasticity of leader to demand of product $i$ produced by factory $j$ at period $t$

$\beta_{i j^{\prime} t}^{\prime} \quad$ Price elasticity of follower to demand of product $i$ produced by factory $j^{\prime}$ at period $t$

$\gamma_{i j t} \quad$ Price elasticity of rival-demand from leader for product $i$ produced by factory $j$ at period $t$

$\gamma_{i j^{\prime} t}^{\prime} \quad$ Price elasticity of rival-demand from follower for product $i$ produced by factory $j^{\prime}$ at period $t$

$D_{i t}^{s} \quad$ Demand of product $i$ at period $t$ under scenario $s$

$c p_{i j k t}^{s} \quad$ The cost of producing each unit of final product $i$ in factory $j$ by workforce at level $k$ during period $t$ under scenario $s$

$c l_{j k t}^{s} \quad$ Labor cost at level $k$ in factory $j$ during period $t$ under scenario $s$

$c I f_{i j t}^{s} \quad$ Inventory cost of final product $i$ in factory $j$ during period $t$ under scenario $s$

$c w H_{j k t} \quad$ Cost of hiring workforce at level $k$ in factory $j$ during period $t$

$c w L_{j k t} \quad$ Cost of laying-off workforce at level $k$ in factory $j$ during period $t$

$a_{i k} \quad$ The time needed to produce final product $i$ by workforce at level $k$

$b_{i k} \quad$ The machinery time needed to produce final product $i$ by workforce at level $k$ 
$C_{k} \quad$ Working hours of workforce at level $k$ in every period

$L P L_{i j t} \quad$ Minimum selling price of final product $i$ produced by factory $j$ (leader) at period $t$

$L P F_{i j^{\prime} t} \quad$ Minimum selling price of final product $i$ produced by factory $j^{\prime}$ (rival) at period $t$

$U P L_{i j t} \quad$ Maximum selling price of final product $i$ produced by factory $j$ (leader) at period $t$

$U P F_{i j^{\prime} t} \quad$ Maximum selling price of final product $i$ produced by factory $j^{\prime}$ (rival) at period $t$

$C a p L_{j t} \quad$ Maximum available inventory capacity of all leader products in factory $j$ at period $t$

$C_{a p} F_{i t} \quad$ Maximum selling capacity of product $i$ by follower companies in the market at period $t$

$v f_{i} \quad$ Space occupied by a unit of product $i$

$M_{j t} \quad$ Maximum available machinery time in factory $j$ at period $t$

$c k_{i j t} \quad$ Cost of setting up the production of final product $i$ in factory $j$ at period $t$

$I w_{j k} \quad$ Number of initial workforce at level $k$ in factory $j$

$p_{s} \quad$ Probability of scenario $s$

$\lambda \quad$ Fixed factor of deviation

$\omega \quad$ Penalty parameter

Large A large positive number

Decision variables:

$p_{i j k t}^{s} \quad$ Production amount of final product $i$ in factory $j$ by workforce at level $k$ during period $t$ under scenario $s$

$p r_{i j t} \quad$ Selling price of final product $i$ produced by factory $j$ (leader) at period $t$

$p r_{i j^{\prime} t}^{\prime} \quad$ Selling price of final product $i$ produced by factory $j^{\prime}$ (rival) at period $t$

$I f_{i j t}^{s} \quad$ Amount of inventory of final product $i$ in factory $j$ at period $t$ under scenario $s$

$x_{i j t}^{s} \quad$ Sales amount of final product $i$ produced by factory $j$ (leader) at period $t$

$x_{i j^{\prime} t}^{s} \quad$ Sales amount of final product $i$ produced by factory $j^{\prime}$ (rival) at period $t$

$d L_{i j t}^{s} \quad$ Amount of potential demand from leader for final product $i$ produced by factory $j$ at period $t$ under scenario $s$

$\begin{array}{ll}d F_{i j^{\prime} t}^{s} & \begin{array}{l}\text { Amount of potential demand from } \\ \text { rival companies for final product } i\end{array} \\ & \begin{array}{l}\text { produced by factory } j^{\prime} \text { at period } t \\ \text { under scenario } s\end{array} \\ W_{j k t} & \begin{array}{l}\text { Number of workforce at level } k \text { in } \\ \text { factory } j \text { at period } t\end{array} \\ w H_{j k t} & \begin{array}{l}\text { Number of workforce at level } k \text { hired } \\ \text { in factory } j \text { at period } t\end{array} \\ w L_{j k t} & \begin{array}{l}\text { Number of workforce at level } k \text { laid-off } \\ \text { in factory } j \text { at period } t\end{array} \\ k_{i j t} & \text { The binary variable of setting up final } \\ & \text { product } i \text { in factory } j \text { at period } t \\ \delta_{i t}^{s} & \text { The amount of higher response to } \\ & \text { market demand (oversupply) for } \\ \text { product } i \text { at period } t \text { under scenario } s \\ \text { Deviation measure in scenario } s\end{array}$

Now, the bi-level APP model is developed based on the real conditions of the competitive market of the leader and follower companies. The costs of the leader include Production Cost (PC), Setup Cost (SC), Workforce changing Cost (WC), Inventory Cost (IC), and Labor Cost (LC). Each of these costs, sales revenue for the leader company (RevL), and sales revenue for the follower companies (RevF) are obtained through the following equations:

Sales revenue for the leader company:

$$
\operatorname{RevL_{s}}=\sum_{i} \sum_{j} \sum_{t} p r_{i j t} \cdot x_{i j t}^{s} .
$$

Sales revenue for the follower companies:

$$
R e v F_{s}=\sum_{i} \sum_{j^{\prime}} \sum_{t} p r_{i j^{\prime} t}^{\prime} \cdot x_{i j^{\prime} t}^{\prime s} .
$$

Production cost:

$$
P C_{s}=\sum_{i} \sum_{j} \sum_{k} \sum_{t} c p_{i j k t}^{s} . p_{i j k t}^{s} .
$$

Setup cost:

$$
S C_{s}=\sum_{i} \sum_{j} \sum_{t} c k_{i j t} . k_{i j t} .
$$

Workforce changing cost:

$$
\begin{aligned}
W C_{s}= & \sum_{j} \sum_{k} \sum_{t}\left(c w H_{j k t} . w H_{j k t}\right. \\
& \left.+c w L_{j k t} . w L_{j k t}\right) .
\end{aligned}
$$

Inventory cost:

$$
I C_{s}=\sum_{i} \sum_{j} \sum_{t} c I f_{i j t}^{s} \cdot I f_{i j t}^{s} .
$$

Labor cost: 


$$
L C_{s}=\sum_{j} \sum_{k} \sum_{t} c l_{j k t}^{s} . W_{j k t} .
$$

Eq. (7) shows the sales revenue for the leader company, which is obtained by multiplying the selling price of its products by the amount of sales. Eq. (8) indicates the sales revenue for the rival companies. Eqs. (7) and (8) are nonlinear. Eqs. (9) and (10) show the total production cost and setup cost for the leader company, respectively. Eq. (11) shows the workforce changing cost including hiring and laying off. Eq. (12) shows the cost of inventory in warehouse and Eq. (13) shows the labor cost of different levels of workers for the leader company. In the following, objective functions of the leader and follower as well as the problem constraints will be separately presented. The leader's problem including its objective function and constraints is modeled as follows:

Leader:

$$
\begin{aligned}
\min z_{L}= & \sum_{s} p_{s}\left(P C_{s}+S C_{s}+W C_{s}+I C_{s}\right. \\
& \left.+L C_{s}-\operatorname{Rev} L_{s}\right)+\lambda \sum_{s} p_{s}\left[\left(P C_{s}\right.\right. \\
& \left.+S C_{s}+W C_{s}+I C_{s}+L C_{s}-\operatorname{Rev} L_{s}\right) \\
& -\sum_{s^{\prime}} p_{s^{\prime}}\left(P C_{s^{\prime}}+S C_{s^{\prime}}+W C_{s^{\prime}}\right. \\
& \left.\left.+I C_{s^{\prime}}+L C_{s^{\prime}}-R e v L_{s^{\prime}}\right)+2 \theta_{s}\right] \\
& +\omega \sum_{i} \sum_{t} \sum_{s} p_{s} . \delta_{i t}^{s}
\end{aligned}
$$

s.t.:

$$
\begin{array}{ll}
I f_{i j t}^{s}=I f_{i j, t-1}^{s}+\sum_{k}\left(p_{i j k t}^{s}\right)-x_{i j t}^{s} & \forall i, j, t, s,(15) \\
\sum_{j} d L_{i j t}^{s}+\sum_{j^{\prime}} d F_{i j^{\prime} t}^{s}-\delta_{i t}^{s} \leq D_{i t}^{s} & \forall i, t, s, \quad(16) \\
d L_{i j t}^{s} \leq \alpha_{i j t}-\beta_{i j t} . p r_{i j t}+\gamma_{i j t} . p r_{i j^{\prime} t}^{\prime} & \forall i, j, j^{\prime}, t, s, \\
x_{i j t}^{s} \leq d L_{i j t}^{s} & \forall i, j, t, s,(18) \\
L P L_{i j t} \leq p r_{i j t} \leq U P L_{i j t} & \forall i, j, t, \quad(19) \\
\sum_{i} v f_{i} . I f_{i j t}^{s} \leq C a p L_{j t} & \forall j, t, s, \quad(20) \\
W_{j k t}=W_{j k, t-1}+w H_{j k t}-w L_{j k t} & \forall j, k, t, \quad(21) \\
\sum_{i} a_{i k} . p_{i j k t}^{s} \leq C_{k} . W_{j k t} & \forall j, k, t, s,(22)
\end{array}
$$

$$
\begin{array}{cc}
\sum_{i} \sum_{k} b_{i k} . p_{i j k t}^{s} \leq M_{j t} & \forall j, t, s, \\
\sum_{k} p_{i j k t}^{s} \leq \text { Large. } k_{i j t} & \forall i, j, t, s, \quad(24) \\
\left(P C_{s}+S C_{s}+W C_{s}+I C_{s}+L C_{s}-R e v L_{s}\right) & \forall s, \\
-\sum_{s^{\prime}} p_{s^{\prime}}\left(P C_{s^{\prime}}+S C_{s^{\prime}}+W C_{s^{\prime}}+I C_{s^{\prime}}\right. \\
\left.+L C_{s^{\prime}}-R e v L_{s^{\prime}}\right)+\theta_{s} \geq 0 \quad \forall L_{i j t}^{s}, p_{i j k t}^{s}, I f_{i j t}^{s}, x_{i j t}^{s}, d L_{i j t}^{s}, W_{j k t}, w H_{j k t}, w L_{j k t}, \delta_{i t}^{s}, \\
\theta_{s} \geq 0, \quad k_{i j t} \in\{0,1\} \quad \forall i, j, k, t, s .
\end{array}
$$

In the upper-level objective function, i.e., Eq. (14), the company plays the role of a leader. This objective function, which should be minimized, is equal to the sum of the above-mentioned costs of the leader company minus its sales revenue. According to Mulvey et al.'s robust optimization approach [10], regarding various scenarios, the objective function of the leader in our BLP includes three terms. The first and second terms are the mean and variance of the total loss, respectively, which measure solution robustness. The third term demonstrates model robustness regarding the infeasibility of the control constraints (16) under scenario $s$.

Eq. (15) is an equilibrium constraint used to determine the production amount of a product as well as the amount of inventory stored in the warehouse. Eq. (16) is a control equilibrium constraint, which determines the portions of the market demand that the leader and the follower can potentially have as well as the over-fulfillment amount of customer demand (oversupply). In fact, this constraint implies that the total demand responded by the leader and the follower should not exceed the total market demand. If in period $t$, the total potential market demand for the leader and follower, i.e., $\sum_{j} d L_{i j t}^{s}+\sum_{j^{\prime}} d F_{i j^{\prime} t}^{s}$, is higher than demand $\left(D_{i t}^{s}\right)$, then the total market demand that becomes potential in reality in period $t$ will be equal to $\sum_{j} d L_{i j t}^{s}+\sum_{j^{\prime}} d F_{i j^{\prime} t}^{s}=D_{i t}^{s}$ and $\delta_{i t}^{s}=$ $\sum_{j} d L_{i j t}^{s}+\sum_{j^{\prime}} d F_{i j^{\prime} t}^{s}-D_{i t}^{s}$ indicates the oversupply. It should be noted that $\delta_{i, t-1}^{s}$ is not the oversupply for period $t$, whereas, if $\sum_{j} d L_{i j t}^{s}+\sum_{j^{\prime}} d F_{i j^{\prime} t}^{s}$ is less than the demand, then the deviation will be equal to zero $\left(\delta_{i t}^{s}=0\right)$ after minimizing. Consequently, the total market demand will not be satisfied.

Eq. (17) is the relation between demand and price, which has been written for the leader with regard to Eq. (5). Eq. (18) implies that the amount of sales of the leader for a particular product should not exceed its potential demand. Eq. (19) ensures that the 
selling price of the leader is between the minimum and maximum.

According to Eq. (20), it is ensured that the inventory level of a certain company is less than its maximum available inventory capacity. Eq. (21) implies that the available workforce in each period is equal to the workforce in the previous period plus the change in the number of workforce in the current period. Considering the initial number of workforce in factory $j\left(I w_{j k}\right)$, this equation will be broken into Eqs. (27) and (28):

$$
\begin{array}{ll}
W_{j k t}=I w_{j k}+w H_{j k t}-w L_{j k t} & \forall j, k, t=1, \\
W_{j k t}=W_{j k, t-1}+w H_{j k t}-w L_{j k t} & \forall j, k, t \geq 2 .
\end{array}
$$

Eq. (22) restricts the production to the total hours available to the workforce at level $k$. Eq. (23) restricts the production in each period by workforce at level $k$ to the available capacity of machinery production. Eq. (24) expresses the relationship between production of a product and production setup. Eq. (25) has been used in relation to robust optimization method to linearize the objective function of Mulvey et al.'s approach for the leader. Finally, Eq. (26) defines the decision variables of the leader.

In the following, the follower's problem including its objective function and constraints is modeled:

Follower:

$$
\max z_{F}=\sum_{s} p_{s} \cdot \operatorname{Rev} F_{s}
$$

s.t.

$$
\begin{array}{ll}
d F_{i j^{\prime} t}^{s} \leq \alpha_{i j^{\prime} t}^{\prime}-\beta_{i j^{\prime} t}^{\prime} \cdot p r_{i j^{\prime} t}^{\prime}+\gamma_{i j^{\prime} t}^{\prime} \cdot p r_{i j t} \\
\forall i, j, j^{\prime}, t, s, & \\
x_{i j^{\prime} t}^{\prime s} \leq d F_{i j^{\prime} t}^{s} & \forall i, j^{\prime}, t, s, \\
\sum_{j^{\prime}} d F_{i j^{\prime} t}^{s} \leq C a p F_{i t} & \forall i, t, s, \\
L P F_{i j^{\prime} t} \leq p r_{i j^{\prime} t}^{\prime} \leq U P F_{i j^{\prime} t} & \forall i, j^{\prime}, t, \\
p r_{i j^{\prime} t}^{\prime}, x_{i j^{\prime} t}^{\prime s}, d F_{i j^{\prime} t}^{s} \geq 0 & \forall i, j^{\prime}, t, s .
\end{array}
$$

Eq. (29) presents the objective function of rival companies, which act in the BLP as the follower. Since the main goal in considering uncertainty in this research is to make the presented model more robust for the leader and the objective of the follower is of less importance, Eq. (29) is for maximization of the expected value of sales revenue of the rival companies.

Eq. (30) presents the relation between the demand and price for the follower with regard to Eq. (6). Eq. (31) indicates that the sales amount of the follower for a particular product should not exceed the demand level that becomes potential for the follower. Eq. (32) expresses that the total potential demand for a certain product of the rival companies cannot exceed their sales capacity. Eq. (33) implies that the selling price of the follower should be between the minimum and maximum. Finally, Eq. (34) defines the decision variables of the follower. The constraints of the leader and the follower determine the feasible region for the leader.

\subsection{Linearization of the objective functions}

First, it should be noted that BLP models are naturally nonlinear. However, we address the linearization of the bi-level function in the next section by transforming it into a uni-level one. As it is obvious, Eqs. (7) and (8) are nonlinear due to the multiplication of two continuous variables. Thus, they are linearized using a three-step approximate linearization method, which has been provided by researchers in the literature for linearizing such non-linear status [72]. First, Eq. (7) and then, Eq. (8) are linearized.

First step: For each of the continuous variables of Eq. (7), considering the constraints of the presented model, an upper and a lower bound are determined by Eqs. (35) and (36):

$$
\begin{array}{ll}
L P L_{i j t} \leq p r_{i j t} \leq U P L_{i j t} & \forall i, j, t, \\
0 \leq x_{i j t}^{s} \leq D_{i t}^{s} & \forall i, j, t, s .
\end{array}
$$

Second step: Multiplication of the two continuous variables of Eq. (7) is equal to, and replaced by, another continuous variable:

$$
O 1_{i j t}^{s}=p r_{i j t} \cdot x_{i j t}^{s} \quad \forall i, j, t, s .
$$

Third step: Eqs. (38) and (39) are added to the constraints of the original model:

$$
\begin{array}{ll}
0 \leq O 1_{i j t}^{s} \leq D_{i t}^{s} \cdot p r_{i j t} & \forall i, j, t, s, \\
L P L_{i j t} \cdot x_{i j t}^{s} \leq O 1_{i j t}^{s} \leq U P L_{i j t} \cdot x_{i j t}^{s} & \forall i, j, t, s .
\end{array}
$$

The same steps are also taken for Eq. (8):

First step: An upper and a lower bound are determined for each of the continuous variables of Eq. (8):

$$
\begin{array}{ll}
L P F_{i j^{\prime} t} \leq p r_{i j^{\prime} t}^{\prime} \leq U P F_{i j^{\prime} t} & \forall i, j^{\prime}, t, \\
0 \leq x_{i j^{\prime} t}^{\prime s} \leq C a p F_{i t} & \forall i, j, t, s .
\end{array}
$$

Second step: Multiplication of the two continuous variables is replaced by another continuous variable:

$$
O 2_{i j^{\prime} t}^{s}=p r_{i j^{\prime} t}^{\prime} . x_{i j^{\prime} t}^{s} \quad \forall i, j^{\prime}, t, s .
$$


Third step: Eqs. (43) and (44) are added to the original model:

$$
\begin{array}{lr}
0 \leq O 2_{i j^{\prime} t}^{s} \leq C a p F_{i t} \cdot p r_{i j^{\prime} t}^{\prime} & \forall i, j^{\prime}, t, s, \\
& (43) \\
L P F_{i j^{\prime} t} \cdot x_{i j^{\prime} t}^{\prime s} \leq O 2_{i j^{\prime} t}^{s} \leq U P F_{i j^{\prime} t} . x_{i j^{\prime} t}^{\prime s} & \forall i, j^{\prime}, t, s .
\end{array}
$$

\subsection{Transforming the bi-level problem into a} uni-level one using the KKT conditions

To transform this bi-level programming problem into an ordinary uni-level problem, because all of the variables related to the follower are continuous, the KKT conditions can be used. Using such conditions, the objective function of the follower is replaced by constraints called constant and complementary conditions, which are added to the problem constraints with the objective function of the leader. In the following, objective function of the follower, in linear form, and its constraints are rewritten.

Follower:

$$
\max z_{F}=\sum_{i} \sum_{j^{\prime}} \sum_{t} \sum_{s} p_{s} . O 2_{i j^{\prime} t}^{s},
$$

s.t.:

$$
\begin{array}{ll}
d F_{i j^{\prime} t}^{s} \leq \alpha_{i j^{\prime} t}^{\prime}-\beta_{i j^{\prime} t}^{\prime} . p r_{i j^{\prime} t}^{\prime}+\gamma_{i j^{\prime} t}^{\prime} \cdot p r_{i j t} \\
\forall i, j, j^{\prime}, t, s, & \forall i, j^{\prime}, t, s, \\
x_{i j^{\prime} t}^{\prime s} \leq d F_{i j^{\prime} t}^{s} & \forall i, t, s, \\
\sum_{j^{\prime}} d F_{i j^{\prime} t}^{s} \leq C a p F_{i t} & \forall i, j^{\prime}, t, \\
p r_{i j^{\prime} t}^{\prime} \leq U P F_{i j^{\prime} t} & \forall i, j^{\prime}, t, \\
p r_{i j^{\prime} t}^{\prime} \geq L P F_{i j^{\prime} t} & \forall i, j^{\prime}, t, s, \\
O 2_{i j^{\prime} t}^{s} \leq C a p F_{i t} \cdot p r_{i j^{\prime} t}^{\prime} & \forall i, j^{\prime}, t, s, \\
O 2_{i j^{\prime} t}^{s} \geq L P F_{i j^{\prime} t} . x_{i j^{\prime} t}^{s} & \forall i, j^{\prime}, t, s, \\
O 2_{i j^{\prime} t}^{s} \leq U P F_{i j^{\prime} t} . x_{i j^{\prime} t}^{\prime s} & \\
x_{i j^{\prime} t}^{s}, d F_{i j^{\prime} t}^{s}, p r_{i j^{\prime} t}^{\prime}, O 2_{i j^{\prime} t}^{s} \geq 0 .
\end{array}
$$

Now, the KKT conditions should be written for the above model in order to transform the bi-level model into a uni-level one. For this purpose, first, all the constraints of the problem, especially the constraints of non-negative variables, should be written as the standard state of a maximization problem. $u 1$ and $u 10$ are supposed to be variables related to the KKT conditions for the constraints of the above model. It should be noted that $u 9$ and $u 10$ are considered for $-x^{\prime} \leq 0$ and $-d F \leq 0$, respectively. It is not needed to define two variables related to the KKT conditions for variables $p r^{\prime}$ and $O 2$ due to the application of Constraints (50) and (52) and their intersection with $-p r^{\prime} \leq 0$ and $-O 2 \leq 0$, respectively. Now, the KKT conditions can be written as follows:

$$
\begin{aligned}
& p_{s}=u 6_{i j^{\prime} t}^{s}-u 7_{i j^{\prime} t}^{s}+u 8_{i j^{\prime} t}^{s} \quad \forall i, j^{\prime}, t, s, \\
& 0=\beta_{i j^{\prime} t}^{\prime} . u 1_{i j j^{\prime} t}^{s}+u 4_{i j^{\prime} t}-u 5_{i j^{\prime} t}-C a p F_{i t} . u 6_{i j^{\prime} t}^{s} \\
& \forall i, j, j^{\prime}, t, s, \\
& 0=u 2_{i j^{\prime} t}^{s}+L P F_{i j^{\prime} t} \cdot u 7_{i j^{\prime} t}^{s}-U P F_{i j^{\prime} t} \cdot u 8_{i j^{\prime} t}^{s}-u 9_{i j^{\prime} t}^{s} \\
& \forall i, j^{\prime}, t, s, \\
& 0=u 1_{i j j^{\prime} t}^{s}-u 2_{i j^{\prime} t}^{s}+u 3_{i t}^{s}-u 10_{i j^{\prime} t}^{s} \quad \forall i, j, j^{\prime}, t, s, \\
& u 1_{i j j^{\prime} t}^{s} \leq M .\left(1-z 1_{i j j^{\prime} t}^{s}\right) \quad \forall i, j, j^{\prime}, t, s, \\
& -\left(d F_{i j^{\prime} t}^{s}-\alpha_{i j^{\prime} t}^{\prime}+\beta_{i j^{\prime} t}^{\prime} \cdot p r_{i j^{\prime} t}^{\prime}-\gamma_{i j^{\prime} t}^{\prime} \cdot p r_{i j t}\right) \leq M . z 1_{i j j^{\prime} t}^{s} \\
& \forall i, j, j^{\prime}, t, s, \\
& u 2_{i j^{\prime} t}^{s} \leq M \cdot\left(1-z 2_{i j^{\prime} t}^{s}\right) \\
& \forall i, j^{\prime}, t, s, \quad(61) \\
& -\left(x_{i j^{\prime} t}^{s}-d F_{i j^{\prime} t}^{s}\right) \leq M . z 2_{i j^{\prime} t}^{s} \\
& \forall i, j^{\prime}, t, s, \\
& u 3_{i t}^{s} \leq M \cdot\left(1-z 3_{i t}^{s}\right) \\
& \forall i, t, s, \\
& -\left(d F_{i j^{\prime} t}^{s}-C a p F_{i t}\right) \leq M . z 3_{i t}^{s} \\
& \forall i, j^{\prime}, t, s, \\
& u 4_{i j^{\prime} t} \leq M .\left(1-z 4_{i j^{\prime} t}\right) \\
& \forall i, j^{\prime}, t \\
& -\left(p r_{i j^{\prime} t}^{\prime}-U P F_{i j^{\prime} t}\right) \leq M . z 4_{i j^{\prime} t} \quad \forall i, j^{\prime}, t, \\
& u 5_{i j^{\prime} t} \leq M .\left(1-z 5_{i j^{\prime} t}\right) \quad \forall i, j^{\prime}, t, \\
& -\left(-p r_{i j^{\prime} t}^{\prime}+L P F_{i j^{\prime} t}\right) \leq M . z 5_{i j^{\prime} t} \quad \forall i, j^{\prime}, t, \\
& u 6_{i j^{\prime} t}^{s} \leq M \cdot\left(1-z 6_{i j^{\prime} t}^{s}\right) \\
& \forall i, j^{\prime}, t, s, \\
& -\left(O 2_{i j^{\prime} t}^{s}-C a p F_{i t} . p r_{i j^{\prime} t}^{\prime}\right) \leq M . z 6_{i j^{\prime} t}^{s} \\
& \forall i, j^{\prime}, t, s, \\
& u 7_{i j^{\prime} t}^{s} \leq M \cdot\left(1-z 7_{i j^{\prime} t}^{s}\right) \\
& \forall i, j^{\prime}, t, s, \\
& -\left(-O 2_{i j^{\prime} t}^{s}+L P F_{i j^{\prime} t} \cdot x_{i j^{\prime} t}^{s}\right) \leq M . z 7_{i j^{\prime} t}^{s} \\
& \forall i, j^{\prime}, t, s, \\
& u 8_{i j^{\prime} t}^{s} \leq M \cdot\left(1-z 8_{i j^{\prime} t}^{s}\right) \\
& \forall i, j^{\prime}, t, s, \\
& -\left(O 2_{i j^{\prime} t}^{s}-U P F_{i j^{\prime} t} . x_{i j^{\prime} t}^{s}\right) \leq M . z 8_{i j^{\prime} t}^{s} \\
& \forall i, j^{\prime}, t, s,
\end{aligned}
$$




$$
\begin{aligned}
& u 9_{i j^{\prime} t}^{s} \leq M .\left(1-z 9_{i j^{\prime} t}^{s}\right) \\
& \forall i, j^{\prime}, t, s, \\
& -\left(-x_{i j^{\prime} t}^{s}\right) \leq M . z 9_{i j^{\prime} t}^{s} \\
& \forall i, j^{\prime}, t, s, \\
& u 10_{i j^{\prime} t}^{s} \leq M \cdot\left(1-z 10_{i j^{\prime} t}^{s}\right) \\
& \forall i, j^{\prime}, t, s, \\
& -\left(-d F_{i j^{\prime} t}^{s}\right) \leq M . u 10_{i j^{\prime} t}^{s} \\
& \forall i, j^{\prime}, t, s, \\
& d F_{i j^{\prime} t}^{s}-\alpha_{i j^{\prime} t}^{\prime}+\beta_{i j^{\prime} t}^{\prime} \cdot p r_{i j^{\prime} t}^{\prime}-\gamma_{i j^{\prime} t}^{\prime} \cdot p r_{i j t} \leq 0 \\
& \forall i, j, j^{\prime}, t, s, \\
& x_{i j^{\prime} t}^{s}-d F_{i j^{\prime} t}^{s} \leq 0 \\
& \forall i, j^{\prime}, t, s, \\
& \sum_{j^{\prime}}\left(d F_{i j^{\prime} t}^{s}\right)-C a p F_{i t} \leq 0 \\
& \forall i, t, s, \\
& p r_{i j^{\prime} t}^{\prime}-U P F_{i j^{\prime} t} \leq 0 \\
& \forall i, j^{\prime}, t, \\
& -p r_{i j^{\prime} t}^{\prime}+L P F_{i j^{\prime} t} \leq 0 \\
& \forall i, j^{\prime}, t, \\
& O 2_{i j^{\prime} t}^{s}-C a p F_{i t} \cdot p r_{i j^{\prime} t}^{\prime} \leq 0 \\
& \forall i, j^{\prime}, t, s, \\
& -O 2_{i j^{\prime} t}^{s}+L P F_{i j^{\prime} t} \cdot x_{i j^{\prime} t}^{\prime s} \leq 0 \\
& \forall i, j^{\prime}, t, s, \\
& O 2_{i j^{\prime} t}^{s}-U P F_{i j^{\prime} t} . x_{i j^{\prime} t}^{s} \leq 0 \\
& \forall i, j^{\prime}, t, s, \\
& -x_{i j^{\prime} t}^{\prime s} \leq 0 \\
& \forall i, j^{\prime}, t, s, \\
& -d F_{i j^{\prime} t}^{s} \leq 0 \\
& \forall i, j^{\prime}, t, s, \\
& u 1_{i j j^{\prime} t}^{s}, u 2_{i j^{\prime} t}^{s}, \cdots, u 10_{i j^{\prime} t}^{s} \geq 0 \\
& \forall i, j, j^{\prime}, t, s \text {, } \\
& z 1_{i j j^{\prime} t}^{s}, z 2_{i j^{\prime} t}^{s}, \cdots, z 10_{i j^{\prime} t}^{s} \in\{0,1\} \\
& \forall i, j, j^{\prime}, t, s \text {. }
\end{aligned}
$$

Eqs. (55) to (58) are the equations related to the gradient in the KKT method. Eqs. (59) to (78) are the linear states of the complementary slackness conditions. Besides, Eqs. (59) and (60) are in fact the linear state of Eq. (91) and the remaining equations are linearized in the same way.

$$
\begin{aligned}
& u 1_{i j j^{\prime} t}^{s} \cdot\left(d F_{i j^{\prime} t}^{s}-\alpha_{i j^{\prime} t}^{\prime}+\beta_{i j^{\prime} t}^{\prime} \cdot p r_{i j^{\prime} t}^{\prime}-\gamma_{i j^{\prime} t}^{\prime} \cdot p r_{i j t}\right)=0 \\
& \quad \forall i, j, j^{\prime}, t, s .
\end{aligned}
$$

Eqs. (79)-(88) are the main constraints of the follower problem, which should be in the KKT conditions. Finally, Eqs. (89) and (90) define the decision variables. Now, the developed model is a uni-level one in which objective function of the leader is the only objective of the problem and the constraints related to the KKT conditions have been replaced by the second level (follower).

\section{Solution Approach}

\subsection{Introducing the Benders decomposition algorithm}

According to a research by Makui et al. [7], the APP problems are among the strongly NP-hard problems and the use of meta-heuristic methods for solving such problems would not guarantee obtaining accurate and generally optimal solutions. Consequently, to overcome the computational complexities of the presented NPhard problem, we need an efficient algorithm. Applying the BDA guarantees a global and accurate optimum solution. The BDA has a high ability in solving mathematical problems in a large dimension, particularly in probabilistic cases. The BDA was first presented by Benders [73] for solving linear optimization problems with complex variables. Nowadays, it is known as one of the most efficient algorithms for solving largescale instances of Mixed-Integer Problems (MIPs). In BDA, instead of solving the original complex MIP, the problem is decomposed into a master problem (a pure integer programming) and a sub-problem (a linear programming). These two problems are repeatedly solved by applying the solution to one to another until the optimal solution is achieved. The BDA has considerable superiorities over other solution methods (such as meta-heuristic methods) including:

1. This algorithm is based on powerful algebraic concepts;

2. Convergence of the algorithm and achievement of optimal solution have been proved analytically;

3. Each decision-maker can set the optimality gaps precisely.

These profits lead to the utilization of the BDA in various contexts such as APP [7], planning of energy [74], SCND [75], and scheduling [76].

\subsection{Implementing the BDA for the developed model}

To develop the BDA for the current model, first, the Dual Sub-Problem (DSP) and Master Problem (MP) should be formulated. To do this, first, all the 0 and 1 variables, which complicate the problem, should be fixed. These variables are listed below. Then, by replacing these fixed variables in the primary model, the Primal Sub-Problem (PSP) is formulated. In order to avoid repetition, the PSP is not written.

\section{Complex variable:}

$k_{i j t}, \quad z 1_{i j j^{\prime} t}^{s}, \quad z 2_{i j^{\prime} t}^{s}, \quad z 3_{i t}^{s}, \quad z 4_{i j^{\prime} t}, \quad z 5_{i j^{\prime} t}, \quad z 6_{i j^{\prime} t}^{s}$, $z 7_{i j^{\prime} t}^{s}, \quad z 8_{i j^{\prime} t}^{s}, \quad z 9_{i j^{\prime} t}^{s}, \quad z 10_{i j^{\prime} t}^{s}$.

Fixed variable:

$\bar{k}_{i j t}, \quad \overline{z 1}_{i j j^{\prime} t}^{s}, \quad \overline{z 2}_{i j^{\prime} t}^{s}, \quad \overline{z 3}_{i t}^{s}, \quad \overline{z 4}_{i j^{\prime} t}, \quad \overline{z 5}_{i j^{\prime} t}, \quad \overline{z 6}_{i j^{\prime} t}^{s}$, $\overline{z 7}_{i j^{\prime} t}^{s}, \quad \overline{z 8}_{i j^{\prime} t}^{s}, \quad \overline{z 9_{i j^{\prime} t}^{s}}, \quad \overline{z 10}_{i j^{\prime} t}^{s}$. 
If the dual variables corresponding to the PSPconstraints are written as $w$ constraint number (e.g., the variable $w 15_{i j t s}$ is the considered dual variable corresponding to Constraint (15) for $i, j, t$, and $s$ ), then the DSP, which produces an upper bound for the objective function of the original model in each repetition, will be formulated as follows:

$$
\begin{aligned}
& \operatorname{Max}: D S P=\sum_{i t s} D_{i t}^{s} \cdot w 16_{i t s}+\sum_{i j j^{\prime} t s} \alpha_{i j t} . w 17_{i j j^{\prime} t s} \\
& +\sum_{i j t} U P L_{i j t} \cdot w 19 a_{i j t}+\sum_{i j t} L P L_{i j t} \cdot w 19 b_{i j t} \\
& +\sum_{j t s} C a p L_{j t} \cdot w 20_{j t s}+\sum_{j k, t \leq 1} I w_{j k} \cdot w 21_{j k t} \\
& +\sum_{j t s} M_{j t} . w 23_{j t s}+\sum_{i j t s} \text { Large. } \bar{k}_{i j t} . w 24_{i j t s} \\
& +\sum_{i j^{\prime} t s} p_{s} . w 55_{i j^{\prime} t s}+\sum_{i j j^{\prime} t s} M \cdot\left(1-\overline{z 1}_{i j j^{\prime} t}^{s}\right) \cdot w 59_{i j j^{\prime} t s} \\
& +\sum_{i j j^{\prime} t s}\left(M \cdot \overline{z 1}_{i j j^{\prime} t}^{s}-\alpha_{i j^{\prime} t}^{\prime}\right) \cdot w 60_{i j j^{\prime} t s} \\
& +\sum_{i j^{\prime} t s} M \cdot\left(1-\overline{z 2}_{i j^{\prime} t}^{s}\right) \cdot w 61_{i j^{\prime} t s} \\
& +\sum_{i j^{\prime} t s} M \cdot \overline{z 2}_{i j^{\prime} t}^{s} \cdot w 62_{i j^{\prime} t s} \\
& +\sum_{i t s} M \cdot\left(1-\overline{z 3}_{i t}^{s}\right) \cdot w 63_{i t s} \\
& +\sum_{i j^{\prime} t s}\left(M \cdot \overline{z 3}_{i t}^{s}-C a p F_{i t}\right) \cdot w 64_{i j^{\prime} t s} \\
& +\sum_{i j^{\prime} t} M \cdot\left(1-\overline{z 4}_{i j^{\prime} t}\right) \cdot w 65_{i j^{\prime} t} \\
& +\sum_{i j^{\prime} t}\left(M \cdot \overline{z 4}_{i j^{\prime} t}-U P F_{i j^{\prime} t}\right) \cdot w 66_{i j^{\prime} t} \\
& +\sum_{i j^{\prime} t} M \cdot\left(1-\overline{z 5}_{i j^{\prime} t}\right) \cdot w 67_{i j^{\prime} t} \\
& +\sum_{i j^{\prime} t}\left(M \cdot \overline{z 5}_{i j^{\prime} t}+L P F_{i j^{\prime} t}\right) \cdot w 68_{i j^{\prime} t} \\
& +\sum_{i j^{\prime} t s} M \cdot\left(1-\overline{z 6}_{i j^{\prime} t}^{s}\right) \cdot w 69_{i j^{\prime} t s} \\
& +\sum_{i j^{\prime} t s} M \cdot \overline{z 6}_{i j^{\prime} t}^{s} \cdot w 70_{i j^{\prime} t s}
\end{aligned}
$$

$$
\begin{aligned}
& +\sum_{i j^{\prime} t s} M \cdot\left(1-\overline{z 7}_{i j^{\prime} t}^{s}\right) \cdot w 71_{i j^{\prime} t s} \\
& +\sum_{i j^{\prime} t s} M \cdot \overline{z 7}_{i j^{\prime} t}^{s} \cdot w 72_{i j^{\prime} t s} \\
& +\sum_{i j^{\prime} t s} M \cdot\left(1-\overline{z 8}_{i j^{\prime} t}^{s}\right) \cdot w 73_{i j^{\prime} t s} \\
& +\sum_{i j^{\prime} t s} M \cdot \overline{z 8}_{i j^{\prime} t}^{s} \cdot w 74_{i j^{\prime} t s} \\
& +\sum_{i j^{\prime} t s} M \cdot\left(1-\overline{z 9}_{i j^{\prime} t}^{s}\right) \cdot w 75_{i j^{\prime} t s} \\
& +\sum_{i j^{\prime} t s} M \cdot \overline{z 9}_{i j^{\prime} t}^{s} \cdot w 76_{i j^{\prime} t s} \\
& +\sum_{i j^{\prime} t s} M \cdot\left(1-\overline{z 10}_{i j^{\prime} t}^{s}\right) \cdot w 77_{i j^{\prime} t s} \\
& +\sum_{i j^{\prime} t s} M \cdot \overline{z 10}_{i j^{\prime} t}^{s} \cdot w 78_{i j^{\prime} t s} \\
& +\sum_{i j j^{\prime} t s} \alpha_{i j^{\prime} t}^{\prime} . w 79_{i j j^{\prime} t s}+\sum_{i t s} C a p F_{i t} . w 81_{i t s} \\
& +\sum_{i j^{\prime} t} U P F_{i j^{\prime} t} \cdot w 82_{i j^{\prime} t}+\sum_{i j^{\prime} t}\left(-L P F_{i j^{\prime} t}\right) \cdot w 83_{i j^{\prime} t},
\end{aligned}
$$

s.t.:

$$
\begin{gathered}
-w 25_{s}+p_{s} \cdot \sum_{s^{\prime}} w 25_{s^{\prime}}+w 38_{i j t s}+w 39 a_{i j t s} \\
+w 39 b_{i j t s} \leq-p_{s} \quad \forall i, j, t, s
\end{gathered}
$$

$\beta_{i j t} . w 17_{i j j^{\prime} t s}+w 19 a_{i j t}+w 19 b_{i j t}-D_{i t}^{s} \cdot w 38_{i j t s}$

$$
+\gamma_{i j^{\prime} t}^{\prime} \cdot w 60_{i j j^{\prime} t s}-\gamma_{i j^{\prime} t}^{\prime} \cdot w 79_{i j j^{\prime} t s} \leq 0
$$

$$
\forall i, j, j^{\prime}, t, s
$$

$$
\begin{aligned}
-\gamma_{i j t} . w 17_{i j j^{\prime} t s} & -\beta_{i j^{\prime} t}^{\prime} \cdot w 60_{i j j^{\prime} t s}-w 66_{i j^{\prime} t} \\
& +w 68_{i j^{\prime} t}+C a p F_{i t} \cdot w 70_{i j^{\prime} t s} \\
& +\beta_{i j^{\prime} t}^{\prime} . w 79_{i j j^{\prime} t s}+w 82_{i j^{\prime} t}-w 83_{i j^{\prime} t} \\
& -C a p F_{i t} . w 84_{i j^{\prime} t s} \leq 0
\end{aligned}
$$

$\forall i, j, j^{\prime}, t, s$,

$-w 15_{i j t s}+\alpha_{i k} \cdot w 22_{i k t s}+b_{i k} \cdot w 23_{j t s}+w 24_{i j t s}$ 


$$
\begin{aligned}
& +c p_{i j k t}^{s} \cdot w 25_{s}-p_{s} . c p_{i j k t}^{s}\left(\sum_{s^{\prime}} w 25_{s^{\prime}}\right) \\
& \leq p_{s} . c p_{i j k t}^{s} \quad \forall i, j, k, t, s,
\end{aligned}
$$

$$
w 15_{i j t s}-w 15_{i j, t+1, s}+v f_{i} \cdot w 20_{j t s}+c I f_{i j t}^{s} . w 25_{s}
$$$$
-p_{s} . c I f_{i j t}^{s}\left(\sum_{s^{\prime}} w 25_{s^{\prime}}\right) \leq p_{s} . c I f_{i j t}^{s}
$$

$$
\forall i, j, t, s,
$$

$$
w 15_{i j t s}-w 18_{i j t s} \leq 0 \quad \forall i, j, t, s,
$$

$$
-w 62_{i j^{\prime} t s}-L P F_{i j^{\prime} t} . w 72_{i j^{\prime} t s}+U P F_{i j^{\prime} t} . w 74_{i j^{\prime} t s}
$$$$
+w 76_{i j^{\prime} t s}+w 80_{i j^{\prime} t s}+L P F_{i j^{\prime} t} . w 85_{i j^{\prime} t s}
$$$$
-U P F_{i j^{\prime} t} . w 86_{i j^{\prime} t s}-w 87_{i j^{\prime} t s} \leq 0
$$

$$
\forall i, j^{\prime}, t, s,
$$

$-w 16_{i t s} \leq \omega \cdot p_{s} \quad \forall i, t, s$,

$$
w 25_{s} \leq 2 \lambda \cdot p_{s} \quad \forall s,
$$$$
w 16_{i t s}+w 17_{i j j^{\prime} t s}-w 18_{i j t s} \leq 0
$$

$$
\forall i, j, j^{\prime}, t, s,
$$

$$
w 16_{i t s}-w 60_{i j j^{\prime} t s}+w 62_{i j^{\prime} t s}+w 78_{i j^{\prime} t s}
$$$$
+w 79_{i j j^{\prime} t s}-w 80_{i j^{\prime} t s}+w 81_{i t s}-w 88_{i j^{\prime} t s} \leq 0
$$

$$
\forall i, j, j^{\prime}, t, s,
$$$$
-w 21_{j k t} \leq c w H_{j k t} \quad \forall j, k, t,
$$$$
-w 21_{j k t} \leq c w L_{j k t} \quad \forall j, k, t,
$$

$$
w 21_{j k t}-w 21_{j k, t+1}-c_{k} \cdot w 22_{j k t s}+c l_{j k t}^{s} \cdot w 25_{s}
$$

$$
-p_{s} . c l_{j k t}^{s}\left(\sum_{s^{\prime}} w 25_{s^{\prime}}\right) \leq p_{s} . c l_{j k t}^{s}
$$

$$
\forall j, k, t, s,
$$

$$
-w 70_{i j^{\prime} t s}+w 72_{i j^{\prime} t s}-w 74_{i j^{\prime} t s}+w 84_{i j^{\prime} t s}
$$$$
-w 85_{i j^{\prime} t s}+w 86_{i j^{\prime} t s} \leq 0 \quad \forall i, j^{\prime}, t, s,
$$

$$
\beta_{i j^{\prime} t}^{\prime} . w 56_{i j j^{\prime} t s}+w 58_{i j j^{\prime} t s}+w 59_{i j j^{\prime} t s} \leq 0
$$

$$
\forall i, j, j^{\prime}, t, s,
$$

$$
\begin{aligned}
& w 57_{i j^{\prime} t s}-w 58_{i j j^{\prime} t s}+w 61_{i j^{\prime} t s} \leq 0 \\
& \forall i, j, j^{\prime}, t, s, \\
& w 58_{i j j^{\prime} t s}+w 63_{i t s} \leq 0 \quad \forall i, j, j^{\prime}, t, s, \\
& w 56_{i j j^{\prime} t s}+w 65_{i j^{\prime} t} \leq 0 \quad \forall i, j, j^{\prime}, t, s, \\
& -w 56_{i j j^{\prime} t s}+w 67_{i j^{\prime} t} \leq 0 \quad \forall i, j, j^{\prime}, t, s, \\
& w 55_{i j^{\prime} t s}-C a p F_{i t} . w 56_{i j j^{\prime} t s}+w 69_{i j^{\prime} t s} \leq 0 \\
& \forall i, j, j^{\prime}, t, s, \\
& -w 55_{i j^{\prime} t s}+L P F_{i j^{\prime} t . w 5 j^{\prime} t s}+w 71_{i j^{\prime} t s} \leq 0 \\
& \forall i, j^{\prime}, t, s,
\end{aligned}
$$

$w 55_{i j^{\prime} t s}-U P F_{i j^{\prime} t} . w 57_{i j^{\prime} t s}+w 73_{i j^{\prime} t s} \leq 0$

$$
\forall i, j^{\prime}, t, s,
$$

$-w 57_{i j^{\prime} t s}+w 75_{i j^{\prime} t s} \leq 0 \quad \forall i, j^{\prime}, t, s$,

$-w 58_{i j j^{\prime} t s}+w 77_{i j^{\prime} t s} \leq 0 \quad \forall i, j, j^{\prime}, t, s$,

$w 15_{i j t s}, w 21_{j k t}, w 55_{i j^{\prime} t s}, w 56_{i j j^{\prime} t s}, w 57_{i j^{\prime} t s}$,

$$
w 58_{i j j^{\prime} t s} \in U R S \quad \forall i, j, j^{\prime}, t, s,
$$

$w 16_{i t s}, w 17_{i j j^{\prime} t s}, w 18_{i j t s}, w 19 a_{i j t}, w 20_{j t s}$,

$$
\begin{gathered}
w 22_{j k t s}, w 23_{j t s}, w 24_{i j t s}, w 38_{i j t s}, \\
w 39 a_{i j t s}, w 59_{i j j^{\prime} t s}, w 60_{i j j^{\prime} t s}, w 61_{i j^{\prime} t s}, \\
w 62_{i j^{\prime} t s}, w 63_{i t s}, w 64_{i j^{\prime} t s}, w 65_{i j^{\prime} t}, w 66_{i j^{\prime} t}, \\
w 67_{i j^{\prime} t}, w 68_{i j^{\prime} t}, w 69_{i j^{\prime} t s}, w 70_{i j^{\prime} t s}, w 71_{i j^{\prime} t s}, \\
w 72_{i j^{\prime} t s}, w 73_{i j^{\prime} t s}, w 74_{i j^{\prime} t s}, w 75_{i j^{\prime} t s}, w 76_{i j^{\prime} t s}, \\
w 77_{i j^{\prime} t s}, w 78_{i j^{\prime} t s}, w 79_{i j j^{\prime} t s}, w 80_{i j^{\prime} t s}, w 81_{i t s}, \\
w 82_{i j^{\prime} t}, w 83_{i j^{\prime} t}, w 84_{i j^{\prime} t s}, w 85_{i j^{\prime} t s}, w 86_{i j^{\prime} t s}, \\
w 87_{i j^{\prime} t s}, w 88_{i j^{\prime} t s} \leq 0 \quad \forall i, j, j^{\prime}, t, s \\
w 19 b_{i j t}, w 25_{s}, w 39 b_{i j t s} \geq 0 \quad \forall i, j, t, s .
\end{gathered}
$$

Primal variables for the equations above are as follows: 


$\begin{array}{llll}\text { Eq. (93): } & O 1_{i j t}^{s}, & \text { Eq. (94): } & p r_{i, j, t} \\ \text { Eq. (95): } & p r_{i j^{\prime} t}^{\prime}, & \text { Eq. (96): } & p_{i j k t}^{s} \\ \text { Eq. (97): } & I f_{i j t}^{s}, & \text { Eq. (98): } & x_{i j t}^{s} \\ \text { Eq. (99): } & x_{i j^{\prime} t}^{s}, & \text { Eq. (100): } & \delta_{i t}^{s} \\ \text { Eq. (101): } & \theta_{s}, & \text { Eq. (102): } & d L_{i j t}^{s} \\ \text { Eq. (103): } & d F_{i j^{\prime} t}^{s}, & \text { Eq. (104): } & w H_{j k t} \\ \text { Eq. (105): } & w L_{j k t}, & \text { Eq. (106): } & W_{j k t} \\ \text { Eq. (107): } & O 2_{i j^{\prime} t}^{s}, & \text { Eq. (108): } & u 1_{i j j^{\prime} t}^{s} \\ \text { Eq. (109): } & u 2_{i j^{\prime} t}^{s}, & \text { Eq. (110): } & u 3_{i t}^{s} \\ \text { Eq. (111): } & u 4_{i j^{\prime} t}^{s}, & \text { Eq. }(112): & u 5_{i j^{\prime} t} \\ \text { Eq. (113): } & u 6_{i j^{\prime} t}^{s}, & \text { Eq. }(114): & u 7_{i j^{\prime} t}^{s} \\ \text { Eq. (115): } & u 8_{i j^{\prime} t}^{s}, & \text { Eq. }(116): & u 9_{i j^{\prime} t}^{s} \\ \text { Eq. (117): } & u 10_{i j^{\prime} t}^{s} & & \end{array}$

Now, Based on the DSP solution, the MP is formulated as follows. In fact, the MP provides a lower bound on the objective function of the main model in each iteration.

$$
\text { Min } M P=L B
$$

s.t.:

$$
\begin{aligned}
& L B \geq \sum_{s} p_{s} \cdot S C_{s}+\lambda \sum_{s} p_{s}\left[S C_{s}-\sum_{s^{\prime}} p_{s^{\prime}} \cdot S C_{s^{\prime}}\right] \\
& +\sum_{i t s} D_{i t}^{s} \cdot \overline{w 16}_{i t s}+\sum_{i j j^{\prime} t s} \alpha_{i j t} \cdot \overline{w 17}_{i j j^{\prime} t s} \\
& +\sum_{i j t} U P L_{i j t} \cdot \overline{w 19 a}_{i j t}+\sum_{i j t} L P L_{i j t} \cdot \overline{w 19 b}_{i j t} \\
& +\sum_{j t s} \operatorname{CapL}_{j t} \cdot \overline{w 20}_{j t s}+\sum_{j k, t \leq 1} I w_{j k} \cdot \overline{w 21}_{j k t} \\
& +\sum_{j t s} M_{j t} \cdot \overline{w 23}_{j t s}+\sum_{i j t s} \text { Large. } k_{i j t} \cdot \overline{w 24}_{i j t s} \\
& +\sum_{i j^{\prime} t s} p_{s} \cdot \overline{w 55}_{i j^{\prime} t s}+\sum_{i j j^{\prime} t s} M .\left(1-z 1_{i j j^{\prime} t}^{s}\right) \cdot \overline{w 59}_{i j j^{\prime} t s} \\
& +\sum_{i j j^{\prime} t s}\left(M . z 1_{i j j^{\prime} t}^{s}-\alpha_{i j^{\prime} t}^{\prime}\right) \cdot \overline{w 60}_{i j j^{\prime} t s} \\
& +\sum_{i j^{\prime} t s} M \cdot\left(1-z 2_{i j^{\prime} t}^{s}\right) \cdot \overline{w 61}_{i j^{\prime} t s} \\
& +\sum_{i j^{\prime} t s} M . z 2_{i j^{\prime} t}^{s} \cdot \overline{w 62}_{i j^{\prime} t s} \\
& +\sum_{i t s} M \cdot\left(1-z 3_{i t}^{s}\right) \cdot \overline{w 63}_{i t s} \\
& +\sum_{i j^{\prime} t s}\left(M . z 3_{i t}^{s}-C a p F_{i t}\right) \cdot \overline{w 64}_{i j^{\prime} t s}
\end{aligned}
$$

$$
\begin{aligned}
& +\sum_{i j^{\prime} t} M \cdot\left(1-z 4_{i j^{\prime} t}\right) \cdot \overline{w 65}_{i j^{\prime} t} \\
& +\sum_{i j^{\prime} t}\left(M . z 4_{i j^{\prime} t}-U P F_{i j^{\prime} t}\right) \cdot \overline{w 66}_{i j^{\prime} t} \\
& +\sum_{i j^{\prime} t} M \cdot\left(1-z 5_{i j^{\prime} t}\right) \cdot \overline{w 67}_{i j^{\prime} t} \\
& +\sum_{i j^{\prime} t}\left(M . z 5_{i j^{\prime} t}+L P F_{i j^{\prime} t}\right) \cdot \overline{w 6}_{i j^{\prime} t} \\
& +\sum_{i j^{\prime} t s} M \cdot\left(1-z 6_{i j^{\prime} t}^{s}\right) \cdot \overline{w 69}_{i j^{\prime} t s} \\
& +\sum_{i j^{\prime} t s} M . z 6_{i j^{\prime} t}^{s} \cdot \overline{w 70}_{i j^{\prime} t s} \\
& +\sum_{i j^{\prime} t s} M \cdot\left(1-z 7_{i j^{\prime} t}^{s}\right) \cdot \bar{w}_{i j^{\prime} t s} \\
& +\sum_{i j^{\prime} t s} M . z 7_{i j^{\prime} t}^{s} \cdot \overline{w 72}_{i j^{\prime} t s} \\
& +\sum_{i j^{\prime} t s} M \cdot\left(1-z 8_{i j^{\prime} t}^{s}\right) \cdot \overline{w 73}_{i j^{\prime} t s} \\
& +\sum_{i j^{\prime} t s} M . z 8_{i j^{\prime} t}^{s} \cdot \overline{w 74}_{i j^{\prime} t s} \\
& +\sum_{i j^{\prime} t s} M \cdot\left(1-z 9_{i j^{\prime} t}^{s}\right) \cdot \overline{w 75}_{i j^{\prime} t s} \\
& +\sum_{i j^{\prime} t s} M . z 9_{i j^{\prime} t}^{s} \cdot \overline{w 76}_{i j^{\prime} t s} \\
& +\sum_{i j^{\prime} t s} M \cdot\left(1-z 10_{i j^{\prime} t}^{s}\right) \cdot \bar{w} 7 \overline{7}_{i j^{\prime} t s} \\
& +\sum_{i j^{\prime} t s} M . z 10_{i j^{\prime} t}^{s} \cdot \bar{w}_{i j^{\prime} t s}+\sum_{i j j^{\prime} t s} \alpha_{i j^{\prime} t}^{\prime} \cdot \overline{w 79}_{i j j^{\prime} t s} \\
& +\sum_{i t s} C a p F_{i t} \cdot \overline{w 81}_{i t s}+\sum_{i j^{\prime} t} U P F_{i j^{\prime} t} \cdot \overline{w 82}_{i j^{\prime} t} \\
& +\sum_{i j^{\prime} t}\left(-L P F_{i j^{\prime} t}\right) \cdot \overline{w 83}_{i j^{\prime} t}
\end{aligned}
$$

The right side of Eq. $(123) \leq 0$,

$$
\begin{aligned}
& k_{i j t}, z 1_{i j j^{\prime} t}^{s}, z 2_{i j^{\prime} t}^{s}, \cdots, z 10_{i j^{\prime} t}^{s} \in\{0,1\} \\
& \quad \forall i, j, j^{\prime}, t, s .
\end{aligned}
$$

In the MP, the default values for the binary variables, which were considered equal to 1 , are not used. In 
fact, the MP tries to specify the optimum values of these variables. In iterations that the DSP cannot attain a feasible solution for given values of the binary variables, a feasibility cut based on Eq. (123) will be added to the MP. On the other hand, if the DSP attains a feasible solution for given values of the binary variables, then an optimality cut based on Eq. (122) will be added to the MP. Now, after solving the MP, better values of the binary variables can be achieved by using the dual theory. In fact, based on the dual coefficients, Eq. (122) determines which binary variables should retain their coefficients, which should be decreased to zero, and which should get the value of 1. Dual variables derived from the DSP solution indicate the extreme points. Usually, at the beginning of the execution of the BDA, Lower Bound (LB) and Upper Bound (UB) are considered equal to $-\infty$ and $+\infty$, respectively. However, it is preferred to determine a possible smaller interval at the beginning of the algorithm. But considering the objective function of the proposed model, which indicates the loss, the UB and $\mathrm{LB}$ cannot be more restricted at the starting of the algorithm.

\subsection{Steps of the proposed $B D A$}

1. Set the values of $\mathrm{LB}, \mathrm{UB}$, and the binary variables equal to $-\infty,+\infty$, and 1 , respectively.

2. Solve the DSP and obtain the values of dual variables. Subsequently, calculate the UB using this equation:

$$
\begin{aligned}
U B= & \min \left(U B, \sum_{s} p_{s} \cdot S C_{s}\right. \\
& \left.+\lambda \sum_{s} p_{s}\left[S C_{s}-\sum_{s^{\prime}} p_{s^{\prime}} \cdot S C_{s^{\prime}}\right]+D S P\right) .
\end{aligned}
$$

3. If the DSP is unbounded, add the feasibility cut, i.e., Eq. (123), to the MP and find a feasible vector to continue the BDA. Otherwise, add the optimality cut, i.e., Eq. (122), to the MP.

4. Solve the MP and set the value of the LB equal to the value of its objective function; $L B=M P$.

5. If $U B-L B<\varepsilon$, stop. Otherwise, continue with the second step.

\section{Numerical example}

\subsection{Introducing the case study and data}

In this section, in order to show the efficiency of the bilevel APP model, the developed model and its results are analyzed using the real data of a school notebook manufacturer in Isfahan, named Sarvestan Sepahan Company. Sarvestan Sepahan Co., as the leader, intends to produce a new type of school notebooks, which can be replaced by the existing ones, but the largest rivals of Sarvestan Sepahan Co. have no decision to produce new notebooks. Diversity of the new notebooks produced by the leader company includes eight products $(i=1, \cdots, 8)$, which are produced in two main factories of the company $(j=1,2)$. There are four main factories in the rival companies $\left(j^{\prime}=1, \cdots, 4\right)$. The production period is 12 months $(t=1,2, \cdots, 12)$. According to the previous sales documents, future short-term and long-term contracts, and consumer price index, it can be assumed that the possible economic scenario in the future will be one of the following three: boom, average, and poor. The probability of each scenario is shown in Table 1.

Also, dimensions of the case-study problem are shown in Table 2.

Since Sarvestan Sepahan Co. has higher reputation and selling power in the competitive market, the demand-price elasticity parameters, based on the historical data and regression relations, have been obtained in favor of the leader company. Furthermore, because the products considered in the case study are very similar in terms of market elasticity specifications, it has been supposed that the demand-price elasticity parameters have the same values for all products, factories, and periods. These data are summarized in Table 3 .

Considering five working days in a week and eight working hours in a day, the working hours of workers in each period $\left(C_{k}\right)$ are equal to 40 (for simplicity, for all levels of workforce). The maximum available inventory capacity at factory $j$ in period $t\left(C a p L_{j t}\right)$ for all the factories and periods is equal to 5000 units. The demand for the new notebooks can be predicted using the previous sales amounts and the future longterm and short-term contracts. Some of the demand values is presented in Table 4 .

Table 1. Set of scenarios and their probabilities.

\begin{tabular}{cccc}
\hline Scenario & $\begin{array}{c}\text { Boom } \\
\text { (1) }\end{array}$ & $\begin{array}{c}\text { Average } \\
\text { (2) }\end{array}$ & $\begin{array}{c}\text { Poor } \\
\text { (3) }\end{array}$ \\
\hline Probability of scenario $(P s)$ & 0.2 & 0.6 & 0.2 \\
\hline
\end{tabular}

Table 2. The dimensions of the case study.

\begin{tabular}{cccccc}
\hline $\boldsymbol{I}$ & $\boldsymbol{J}$ & $\boldsymbol{J}^{\prime}$ & $\boldsymbol{K}$ & $\boldsymbol{S}$ & $\boldsymbol{T}$ \\
\hline 8 & 2 & 4 & 5 & 3 & 12 \\
\hline
\end{tabular}

Table 3. The demand-price elasticity parameters.

\begin{tabular}{lccc}
\hline \multirow{2}{*}{$\boldsymbol{L}$ or $\boldsymbol{F}$} & \multicolumn{3}{c}{ Parameter } \\
\cline { 2 - 4 } & $\boldsymbol{\alpha}$ & $\boldsymbol{\beta}$ & $\boldsymbol{\gamma}$ \\
\hline Leader $(L)$ & 8500 & 4 & 3 \\
Follower $(F)$ & 7400 & 5 & 2 \\
\hline
\end{tabular}


Table 4. Some of the demand values related to product of the first type $\left(D_{1 t}^{s}\right)$.

\begin{tabular}{ccccc}
\hline & \multicolumn{4}{c}{$\boldsymbol{T}$} \\
\cline { 2 - 5 } $\boldsymbol{s}$ & $\mathbf{1}$ & $\mathbf{2}$ & $\mathbf{3}$ & $\mathbf{4}$ \\
\hline 1 & 10000 & 9000 & 11000 & 8000 \\
2 & 8000 & 6000 & 9500 & 5500 \\
3 & 6500 & 5000 & 7000 & 4000 \\
\hline
\end{tabular}

Table 5. Minimum and maximum selling prices of the leader and the follower for the first product (Rial).

\begin{tabular}{ccc}
\hline $\begin{array}{c}\text { Minimum or maximum } \\
\left(\times \mathbf{1 0}^{\mathbf{3}}\right)\end{array}$ & $\begin{array}{c}\text { Leader } \\
(\boldsymbol{L})\end{array}$ & $\begin{array}{c}\text { Follower } \\
(\boldsymbol{F})\end{array}$ \\
\hline Minimum price $(L P)$ & 35 & 30 \\
Maximum price $(U P)$ & 60 & 45 \\
\hline
\end{tabular}

Table 6. Some of the production costs $\left(c p_{i 11 t}^{s}\right)$ $\left(\times 10^{3}\right.$ Rial $)$.

\begin{tabular}{|c|c|c|c|c|c|}
\hline \multirow[b]{2}{*}{$i$} & \multirow[b]{2}{*}{$s$} & \multicolumn{4}{|c|}{$T$} \\
\hline & & 1 & 2 & 3 & 4 \\
\hline \multirow{3}{*}{1} & 1 & 1.4 & 1.65 & 1.9 & 1.75 \\
\hline & 2 & 1.1 & 1.15 & 1.35 & 1.2 \\
\hline & 3 & 0.85 & 0.95 & 1.05 & 1 \\
\hline \multirow{3}{*}{2} & 1 & 1.35 & 1.55 & 1.8 & 1.65 \\
\hline & 2 & 1 & 1.05 & 1.2 & 1.15 \\
\hline & 3 & 0.75 & 0.9 & 1 & 0.95 \\
\hline
\end{tabular}

Table 7. Some of the selling prices for the first factory of the leader $\left(\times 10^{3}\right.$ Rial $)$.

\begin{tabular}{ccccc}
\hline & \multicolumn{4}{c}{$\boldsymbol{T}$} \\
\cline { 2 - 5 } $\boldsymbol{i}$ & $\mathbf{1}$ & $\mathbf{2}$ & $\mathbf{3}$ & $\mathbf{4}$ \\
\hline 1 & 40 & 45 & 60 & 55 \\
2 & 50 & 60 & 75 & 65 \\
\hline
\end{tabular}

According to the interviews with a group of experts of the company and with regard to the minimum and maximum production costs of the notebooks, the minimum and maximum prices for the leader and the follower are shown in Table 5.

For the sake of brevity, all the data will not be reported. As an example, the values of the production cost in the first factory of the leader for the first-level workforce are shown in Table 6 .

\subsection{Results and analyses}

In this section, the results with $\lambda=1$ and $\omega=250$ are explained to clarify the solution. Some of the selling prices of the products provided by the leader and the follower companies are shown in Tables 7 and 8, respectively.

According to Tables 7 and 8, the selling prices of
Table 8. Some of the selling prices for the first factory of the follower $\left(\times 10^{3} \mathrm{Rial}\right)$.

\begin{tabular}{ccccc}
\hline & \multicolumn{4}{c}{$\boldsymbol{T}$} \\
\cline { 2 - 5 } $\boldsymbol{i}$ & $\mathbf{1}$ & $\mathbf{2}$ & $\mathbf{3}$ & $\mathbf{4}$ \\
\hline 1 & 20 & 25 & 40 & 30 \\
2 & 25 & 35 & 45 & 35 \\
\hline
\end{tabular}

Table 9. Some of the sales amounts of the leader.

\begin{tabular}{ccccc}
\hline & \multicolumn{4}{c}{$\boldsymbol{T}$} \\
\cline { 2 - 5 } $\boldsymbol{s}$ & $\mathbf{1}$ & $\mathbf{2}$ & $\mathbf{3}$ & $\mathbf{4}$ \\
\hline 1 & 5000 & 4000 & 4500 & 4000 \\
2 & 4000 & 3500 & 4000 & 3000 \\
3 & 2500 & 2000 & 3000 & 3500 \\
\hline
\end{tabular}

Table 10. Some of the sales amounts of the follower.

\begin{tabular}{ccccc}
\hline & \multicolumn{4}{c}{$\boldsymbol{T}$} \\
\cline { 2 - 5 } $\boldsymbol{s}$ & $\mathbf{1}$ & $\mathbf{2}$ & $\mathbf{3}$ & $\mathbf{4}$ \\
\hline 1 & 2000 & 1000 & 1500 & 1000 \\
2 & 1500 & 1000 & 1500 & 1000 \\
3 & 900 & 700 & 800 & 1000 \\
\hline
\end{tabular}

Table 11. Some of the production amounts of the leader.

\begin{tabular}{ccccc}
\hline & \multicolumn{4}{c}{$\boldsymbol{T}$} \\
\cline { 2 - 5 } $\boldsymbol{s}$ & $\mathbf{1}$ & $\mathbf{2}$ & $\mathbf{3}$ & $\mathbf{4}$ \\
\hline 1 & 5000 & 5000 & 4000 & 3500 \\
2 & 4000 & 5000 & 3000 & 3000 \\
3 & 3000 & 3000 & 2000 & 2500 \\
\hline
\end{tabular}

the leader are higher than those of the follower. This result is due to the selling power of the leader in the competitive market as previously mentioned. Tables 9 and 10 represent the sales amounts of the leader and follower companies for the first product provided by the first factory, respectively.

According to Tables 9 and 10, the sales amount of the leader is higher than that of the follower. This result can be due to the higher popularity and selling power of the leader in the competitive market. According to the previous tables, a game has been formed between the leader and the follower to gain the market share and thus, the revenue of the leader is obtained higher than that of the follower. Table 11 represents the production amount of the leader company for the first product, first factory, and first level of workforce.

Due to the high cost of hiring and laying off the workforce in the leader company, there will be no reduction in the number of workforce and only 20 people will be hired in the second factory in the fifth period due to demand growth. Table 12 shows some of 
Table 12. Some of the amounts of inventory.

\begin{tabular}{ccccc}
\hline & \multicolumn{4}{c}{$\boldsymbol{T}$} \\
\cline { 2 - 5 } $\boldsymbol{s}$ & $\mathbf{1}$ & $\mathbf{2}$ & $\mathbf{3}$ & $\mathbf{4}$ \\
\hline 1 & 0 & 0 & 1000 & 500 \\
2 & 0 & 0 & 1500 & 1500 \\
3 & 0 & 500 & 1500 & 500 \\
\hline
\end{tabular}

Table 13. Some of the oversupplies for the first product $\left(\delta_{1 t}^{s}\right)$.

\begin{tabular}{ccccc}
\hline & \multicolumn{4}{c}{$\boldsymbol{T}$} \\
\cline { 2 - 5 } $\boldsymbol{s}$ & $\mathbf{1}$ & $\mathbf{2}$ & $\mathbf{3}$ & $\mathbf{4}$ \\
\hline 1 & 9000 & 6500 & 7000 & 6000 \\
2 & 7500 & 0 & 8500 & 1500 \\
3 & 4500 & 0 & 4000 & 5000 \\
\hline
\end{tabular}

the values of the inventory for the first product in the first factory.

According to the equilibrium equation of the model, the remaining inventory is obtained from the difference between the amounts of production and sales. Some of the oversupply values, which are generally caused by excessive production of the follower companies, are reported in Table 13.

The revenue of the leader and the follower is equal to 10600 and 2330 million Rials, respectively, and as expected, the revenue of the leader is more than that of the follower. The revenue for the leader and the follower as well as various costs of the leader in each scenario are presented in Table 14.

Regarding the probability of each scenario, the expected value for the revenue of the rival, calculated from Table 14, will be equal to 2330 million Rials, which is same as the value of the objective function of the follower. Since the setup cost and workforce changing cost are not dependent on the scenario, they will consequently be equal in all the scenarios. In general, as the economic scenarios worsen, the costs are reduced by the lower need for the product in the market and reduced production. Furthermore, due to the lower sales, the revenues are reduced as well.

\subsection{Trade-off between solution robustness and model robustness}

Carrying out sensitivity analysis of $\omega$, a trade-off can be obtained between the solution robustness and the model robustness. In fact, the role of the weight $\omega$ in the objective function (14) is to find a trade-
Table 15. Sensitivity analysis of the penalty parameter

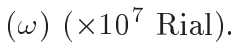

\begin{tabular}{cccc}
\hline $\boldsymbol{\omega}$ & $\begin{array}{c}\text { Solution } \\
\text { robustness }\end{array}$ & $\begin{array}{c}\text { Model } \\
\text { robustness }\end{array}$ & $\begin{array}{c}\text { Objective } \\
\text { function } \\
\text { (profit) }\end{array}$ \\
\hline 0 & 620 & 1.15 & 620 \\
50 & 620 & 1 & 670 \\
100 & 632 & 0.85 & 717 \\
150 & 644 & 0.55 & 726.5 \\
200 & 706 & 0.25 & 756 \\
250 & 755 & 0 & 755 \\
300 & 755 & 0 & 755 \\
\hline
\end{tabular}

off between the solution robustness (closeness to the optimal solution) and model robustness (closeness to the feasible solution). The effect of weight $\omega$ on the solution robustness and the model robustness as well as the objective function is shown in Table 15 . In this table, when $\omega=0$, the solution robustness and objective function will have the minimum values, while the model robustness will have the maximum value. In fact, when $\omega=0, \delta_{i t}^{s}$ in the control constraint (16) will be equal to $+\infty$; thus, a large demand will become potential for the leader and the follower. Consequently, the relevant constraint will not be an obstacle to the production. In this case, the higher total expected response to demand (oversupply) will be at its highest level and thus, $\omega=0$ is not an appropriate choice.

When $\omega=250$, the solution robustness and the objective function will both be equal to 755 , but the model robustness will be equal to zero, the reason of which is that the higher total expected response to demand (oversupply) is equal to zero. Figure 2 shows

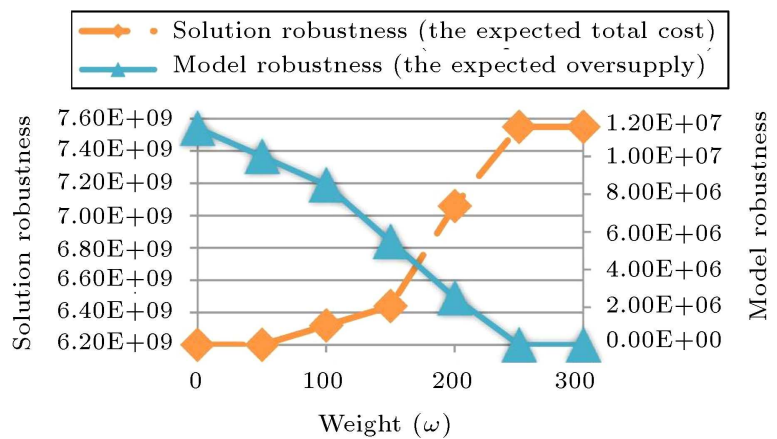

Figure 2. Trade-off between solution robustness and model robustness.

Table 14. The revenue and the cost under each scenario $\left(\times 10^{6} \mathrm{Rial}\right)$.

\begin{tabular}{ccccccccc}
\hline Scenario & $\boldsymbol{R e v} \boldsymbol{L}_{\boldsymbol{s}}$ & $\boldsymbol{R e v \boldsymbol { F } _ { \boldsymbol { s } }}$ & $\boldsymbol{P C}_{\boldsymbol{s}}$ & $\boldsymbol{S C}$ & $\boldsymbol{W C}$ & $\boldsymbol{I C}_{\boldsymbol{s}}$ & $\boldsymbol{L} \boldsymbol{C}_{\boldsymbol{s}}$ & Total cost \\
\hline 1 & 14580 & 4600 & 2390 & 140 & 720 & 155 & 2040 & 5445 \\
2 & 10470 & 1940 & 1720 & 140 & 720 & 130 & 1350 & 4060 \\
3 & 7020 & 1220 & 1200 & 140 & 720 & 105 & 735 & 2900 \\
\hline
\end{tabular}


the trade-off between solution robustness and model robustness with respect to change in $\omega$.

According to Figure 2, with an increase in the value of $\omega$, the solution robustness increases with increasing rate while the model robustness is reduced. This means that for larger values of $\omega$, the solution obtained for realizing each scenario through paying higher total cost is nearly close to the feasible solution. Therefore, for values of $\omega \geq 250$, the solutions obtained for all of the scenarios are almost feasible, because the higher total expected response to demand finally reaches zero and the total expected loss, regardless of the higher response to demand, is not changed after $\omega=250$ onwards. This means that both the factors of solution robustness and model robustness tend to a uniform amount. The obtained results confirm the application of the proposed model and the robust optimization approach to solving the problem.

\subsection{Analysis of bi-level model in presence and absence of competition}

As one of the main contributions of this paper is considering the competition in the APP problem, in this section, we compare the revenue in the presence and absence of competition. Figure 3(a) shows the revenue of Sarvestan Sepahan Co. in the presence and absence of competition. According to this figure, considering the competition between Sarvestan Sepahan Co. and the rival companies leads to the increased revenue of Sarvestan Sepahan Co. as the leader, while according to Figure 3(b), the revenue of rival companies is reduced by considering the competition. This is due to the fact that in the presence of competition, the leader offers a lower price. Thus, it has higher sales and accordingly, will have higher revenue. However, due to the higher power of the leader to attract the market demand, a lower share of sales remains for the follower in competition conditions. Thus, the revenue of the follower is reduced.

The comparison in Figures 3(a) and 3(b) indicates

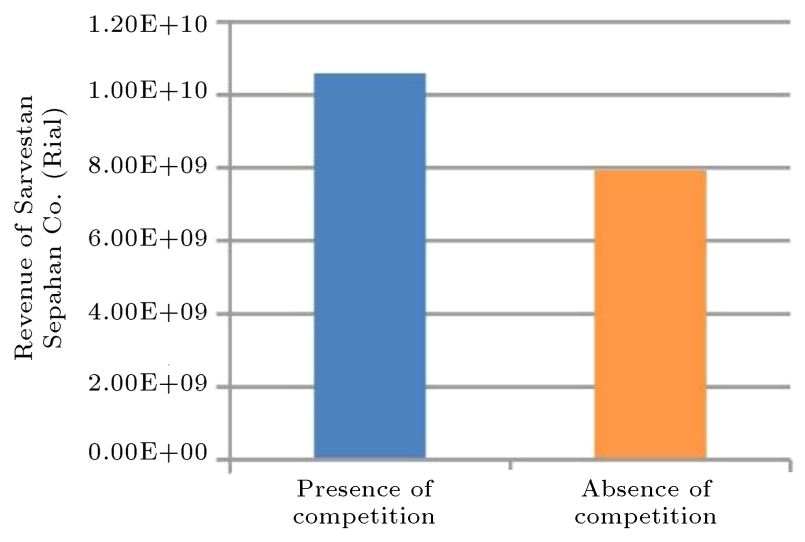

Figure 3(a). Investigation into the revenue of Sarvestan Sepahan Co. in the presence and absence of competition.

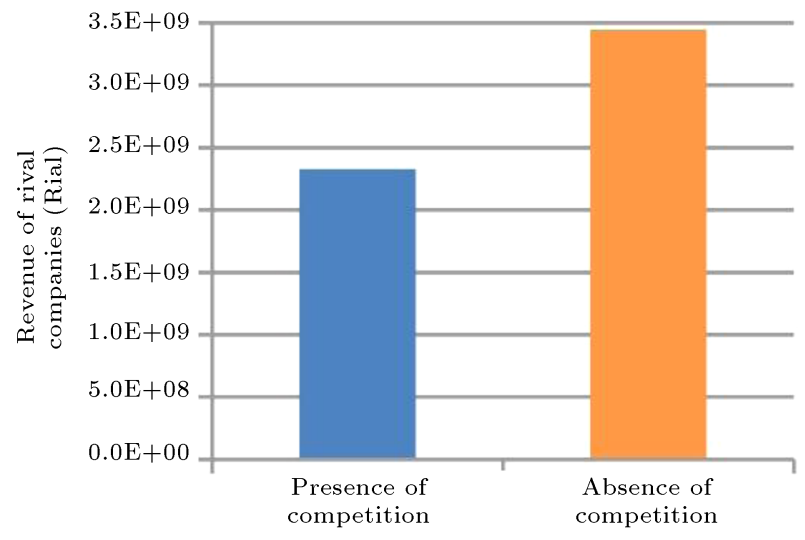

Figure 3(b). Investigation into the revenue of rival companies in the presence and absence of competition.

the effect of considering the competition in a competitive market environment. The decision makers and managers of Sarvestan Sepahan Co. have not ever considered the existing competition. With this research, it is proved that if they had taken the competition into account in the APP, they could have obtained more revenue and higher market share. Therefore, they completely figured out the effect of paying attention to the competition and decided to use this study in order to obtain more revenue. It should also be mentioned that the APP and pricing problem for new products of Sarvestan Sepahan Co. were solved using this study. Besides, the sales manager of this company called this research so valuable for solving the sales and marketing problem in presence of the rival companies.

To carry out a deeper analysis, the downtrend of the leader revenue is investigated by increasing the value of the parameter $\gamma_{i j^{\prime} t}^{\prime}$. Let the downtrend of the leader revenue be defined as the revenue of the leader in case of considering competition minus its revenue when dropping the competition. According to Eq. (30), if the parameter $\gamma_{i j^{\prime} t}^{\prime}$ increases in the presence of competition, then by one unit increase in the selling price of the leader, a higher amount of leader's sales will be captured by the follower. Therefore, the leader will obtain a lower revenue by losing a higher amount of its sales. As a result, the amount of downtrend of the leader revenue will increase in the presence of competition. The results of this analysis are shown in Figure 4.

\subsection{Investigating the efficiency and convergence of the proposed $B D A$}

In this section, the case study is solved using the proposed BDA as well as the conventional solution (CPLEX solver); then, the obtained results are compared. For this purpose, the proposed model has been encoded in GAMS 24.1.2 software and then, executed by CPLEX 12.2.1 solver on a personal computer with Intel Core i7, 2.30 GHz CPU and 6GB Memory. It 


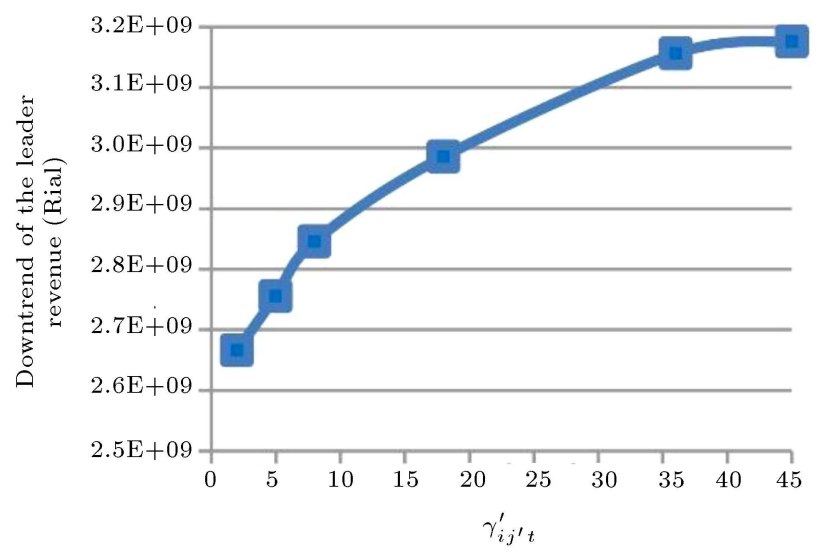

Figure 4. Downtrend of the leader revenue in the presence of competition by increasing the value of the parameter $\gamma_{i j^{\prime} t}^{\prime}$.

should be noted that for the case study, after executing the process in a 60 -minute time limit, the relative optimality gap derived from the BDA is equal to zero, while the relative optimality gap derived from the conventional solution is equal to $4.9 \%$. Comparing the results shows that the proposed BDA has a significantly better time efficiency than the conventional solution and leads to the optimal solution in a shorter time. Table 16 represents some of the information derived by solving the case study and compares the efficiency of the proposed algorithm with that of the conventional method.

According to Table 16, the proposed BDA reports a lower value of the objective function (lower total loss) than the results of the conventional solution in 60 minutes. It should be noted that the optimal solution is obtained in 73 minutes using the conventional solution without considering any time limit. Therefore, it can be concluded that implementation of the proposed algorithm would lead to the exact optimal solution in a reasonable time and the use of this algorithm is justified for solving the developed model. It is noteworthy that the managers of Sarvestan Sepahan Co. have used the conventional solution ever since, but they can find the optimal solution in a shorter time using the proposed BDA in this study.

It also should be noted that the conventional solution requires too long time to report a feasible solution to problems with very large dimensions. Usually, there is a high relative optimality gap between the

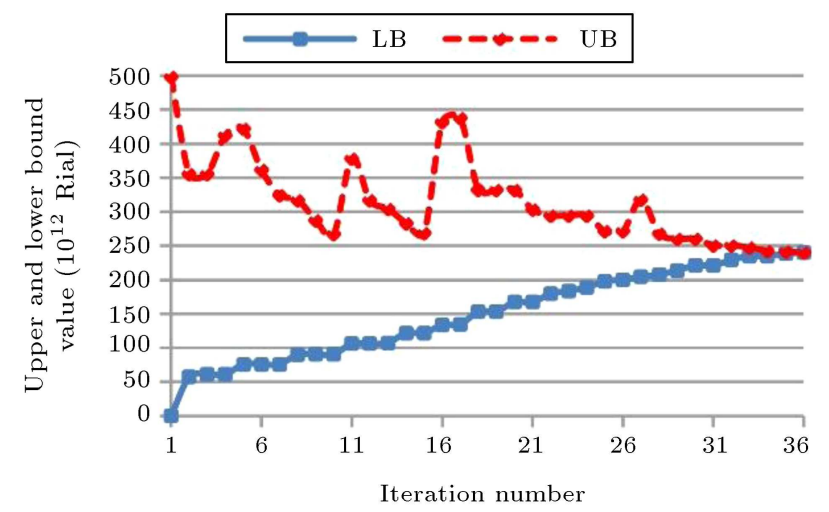

Figure 5. Convergence of the proposed BDA.

reported feasible solution by the conventional solution and the optimal solution. Therefore, the software cannot achieve a near-optimal solution without using the proposed algorithm even in a long time. Accordingly, in addition to the case study, another problem in large dimensions has been designed in numerical experiments to examine the convergence of the BDA. The parameters for this problem have been randomly generated with large dimensions in the range of the parameters of our case study. The generated problem determines the APP for 20 products $(i=1,2, \cdots, 20)$, 12 factories from the leader company $(j=1,2, \cdots, 12)$, 15 factories of the rival companies $\left(j^{\prime}=1, \cdots, 15\right)$, 10 workforce levels $(k=1,2, \cdots, 10), 10$ economic scenarios of uncertainty $(S=1,2, \cdots, 10)$, and a 12 week period $(t=1,2, \cdots, 12)$. It is solved using the BDA in 98 minutes with relative optimality gap of zero. Figure 5 schematically shows the convergence of the proposed algorithm for the mentioned problem with larger dimensions.

\section{Conclusion}

In this research, regarding the intense competition between large manufacturing companies for achieving more amount of sales, a bi-level APP model was developed in order to minimize the total loss of the first level (leader) and maximize revenue of the second level (follower) using the Stackelberg game theory. After linearization, the bi-level model was transformed into an ordinary uni-level one using the KKT conditions. Due to the higher popularity of the leader, according

Table 16. Comparison of efficiencies of the proposed BDA and the conventional solution for the case-study problem.

\begin{tabular}{lccc}
\hline \multirow{2}{*}{ Method } & \multicolumn{3}{c}{ Parameter } \\
\cline { 2 - 4 } & $\begin{array}{r}\text { Run-time } \\
\text { (minutes) }\end{array}$ & $\begin{array}{c}\text { Objective function } \\
\text { (loss, } \times \mathbf{1 0}^{\mathbf{7}} \text { Rial) }\end{array}$ & $\begin{array}{c}\text { Relative optimality } \\
\text { gap (\%) }\end{array}$ \\
\hline Conventional solution & 60 & -718 & 4.9 \\
Proposed BDA & 33 & -755 & 0 \\
\hline
\end{tabular}


to Tables 7-10, the sales amount and price of the leader were obtained higher than those of the follower, which verified the accuracy and validity of the developed model. By the sensitivity analysis under the presence and absence of competition, according to Figure 3(a), it was concluded that the leader would achieve a higher revenue under the presence of competition. Furthermore, in the presence of competition, according to Figure 3(b), the rival companies would achieve a lower revenue because the leader offered a lower price, hence achieving higher sales and consequently, higher revenue. Therefore, the managers of the company under study found out the effect of the competition thoroughly and decided to apply the developed model. To diminish the sensitivity of the developed model to uncertainty in the data [7], the scenario-based robust optimization approach was used. Based on Table 15 and Figure 2, by performing sensitivity analysis of the penalty parameter $\omega$, a trade-off was established between the solution robustness and the model robustness. Also, an optimal APP with an acceptable range of oversupply was obtained. Due to NP-hardness of the problem, the BDA was proposed to overcome the computational complexity in large scale. Furthermore, the efficiency of the proposed BDA was investigated. According to Table 16, this algorithm had better time efficiency than the conventional solution and reported the optimal solution in a shorter time. According to Table 4 and Figure 5, the convergence of the BDA was also proved. The presented bi-level robust model could be used for solving the APP problem and pricing the new products of the manufacturing companies in a real competitive market under uncertainty. The main contributions of our paper compared to the existing literature are summarized as follows:

- We modeled the competition between a leader company with higher selling power and its rival companies in the APP problem simply and efficiently using the BLP by the concept of Stackelberg game. In this study, price of new products was determined using the proposed elasticity relations between demand and price, which created the game between the leader and the follower;

- We considered the inherent uncertainty of the parameters, especially market demand, in a multiscenario framework. Then, we controlled the uncertainty using Mulvey et al.'s robust optimization approach, which made the assumptions closer to the real conditions;

- A powerful BDA was proposed to overcome the computational complexity of the developed NP-hard model in large scales. We also studied a real-life case from Sarvestan Sepahan Co., as a leader, in order to show the accuracy and efficiency of the developed model and the proposed BDA.
There are many future directions for developing the proposed model. First, three- or multi-level modeling of the problem with the third level as minimizing the customer purchase costs will be highly attractive and applicable. Second, the use of other robust optimization approaches with stochastic programming may yield better results. Third, modeling the problem by considering different levels of SC and solving it using other algorithms will lead to valuable research in this regard.

\section{References}

1. Xiao, T. and Yang, D. "Price and service competition of supply chains with risk-averse retailers under demand uncertainty", Int. J. Prod. Econ., 114(1), pp. 187-200 (2008).

2. Rezapour, S., Farahani, R.Z., Ghodsipour, S.H., et al. "Strategic design of competing supply chain networks with foresight", Adv. Eng. Softw., 42(4), pp. 130-141 (2011).

3. Zhang, D. "A network economic model for supply chain versus supply chain competition”, Omega, 34(3), pp. 283-295 (2006).

4. Boyaci, T. and Gallego, G. "Supply chain coordination in a market with customer service competition", Prod. Oper. Manag., 13(1), pp. 3-22 (2004).

5. Anderson, E.J. and Bao, Y. "Price competition with integrated and decentralized supply chains", Eur. J. Oper. Res., 200(1), pp. 227-234 (2010).

6. Fallah, H., Eskandari, H., and Pishvaee, M.S. "Competitive closed-loop supply chain network design under uncertainty", J. Manuf. Syst., 37, pp. 649-661 (2015).

7. Makui, A., Heydari, M., Aazami, A., et al. "Accelerating benders decomposition approach for robust aggregate production planning of products with a very limited expiration date", Comput. Ind. Eng., 100, pp. 34-51 (2016).

8. Nam, S. and Logendran, R. "Aggregate production planning-a survey of models and methodologies", Eur. J. Oper. Res., 61(3), pp. 255-272 (1992).

9. Saharidis, G.K. and Ierapetritou, M.G. "Resolution method for mixed integer bi-level linear problems based on decomposition technique", J. Glob. Optim., 44(1), pp. 29-51 (2009).

10. Mulvey, J.M., Vanderbei, R.J., and Zenios, S.A. "Robust optimization of large-scale systems", Oper. Res., 43(2), pp. 264-281 (1995).

11. Bernstein, F. and Federgruen, A. "A general equilibrium model for industries with price and service competition", Oper. Res., 52(6), pp. 868-886 (2004).

12. Zhang, L. and Rushton, G. "Optimizing the size and locations of facilities in competitive multi-site service systems", Comput. Oper. Res., 35(2), pp. 327-338 (2008). 
13. Bracken, J. and McGill, J.T. "Mathematical programs with optimization problems in the constraints", Oper. Res., 21(1), pp. 37-44 (1973).

14. Candler, W. and Norton, R., Multi-Level Programming and Development Policy, The World Bank (1977).

15. Stackelberg, H.V., The Theory of The Market Economy, Oxford University Press (1952).

16. Vicente, L.N. and Calamai, P.H. "Bilevel and multilevel programming: a bibliography review", Journal of Global Optimization, 5(3). pp. 291-306 (1994).

17. Candler, W., Fortuny-Amat, J., and McCarl, B. "The potential role of multilevel programming in agricultural economics", Am. J. Agric. Econ., 63(3), pp. 521531 (1981).

18. Fortuny-Amat, J. and McCarl, B. "A representation and economic interpretation of a two-level programming problem", J. Oper. Res. Soc., 32(9), pp. 783-792 (1981).

19. Shimizu, K. and Aiyoshi, E. "A new computational method for stackelberg and min-max problems by use of a penalty method", IEEE Transactions on Automatic Control, 26(2). pp. 460-466 (1981).

20. Bard, J.F. and Falk, J.E. "An explicit solution to the multi-level programming problem", Comput. Oper. Res., 9(1), pp. 77-100 (1982).

21. Colson, B., Marcotte, P., and Savard, G. "Bilevel programming: a survey", 4OR, 3(2). pp. 87-107 (2005).

22. Colson, B., Marcotte, P., and Savard, G. "An overview of bilevel optimization", Ann. Oper. Res., 153(1), pp. 235-256 (2007).

23. Bard, J.F., Practical Bilevel Optimization: Algorithms and Applications, Springer Science \& Business Media (1998).

24. Farahani, R.Z., Rezapour, S., Drezner, T., et al. "Competitive supply chain network design: an overview of classifications, models, solution techniques and applications", Omega, 45, pp. 92-118 (2014).

25. Ben-Ayed, O., Boyce, D.E., and Blair, C.E. "A general bilevel linear programming formulation of the network design problem", Transp. Res. Part B Methodol., 22(4), pp. 311-318 (1988).

26. Bard, J.F. and Moore, J.T. "A branch and bound algorithm for the bilevel programming problem", SIAM J. Sci. Stat. Comput., 11(2), pp. 281-292 (1990).

27. Bard, J.F. and Moore, J.T. "An algorithm for the discrete bilevel programming problem", Nav. Res. Logist., 39(3), pp. 419-435 (1992).

28. Edmunds, T.A. and Bard, J.F. "An algorithm for the mixed-integer nonlinear bilevel programming problem", Ann. Oper. Res., 34(1), pp. 149-162 (1992).

29. Yang, H. "Heuristic algorithms for the bilevel origindestination matrix estimation problem", Transp. Res. Part B, 29(4), pp. 231-242 (1995).
30. Maher, M.J., Zhang, X., and Vliet, D.V. "A bilevel programming approach for trip matrix estimation and traffic control problems with stochastic user equilibrium link flows", Transp. Res. Part B Methodol., 35(1), pp. 23-40 (2001).

31. Burgard, A.P., Pharkya, P., and Maranas, C.D. "OptKnock: a bilevel programming framework for identifying gene knockout strategies for microbial strain optimization", Biotechnol. Bioeng., 84(6), pp. 647-657 (2003).

32. Gao, Z., Wu, J., and Sun, H. "Solution algorithm for the bi-level discrete network design problem", Transp. Res. Part B Methodol., 39(6), pp. 479-495 (2005).

33. Shi, C., Lu, J., Zhang, G., and Zhou, H. "An extended branch and bound algorithm for linear bilevel programming", Appl. Math. Comput., 180(2), pp. 529537 (2006).

34. Sun, H., Gao, Z., and Wu, J. "A bi-level programming model and solution algorithm for the location of logistics distribution centers", Appl. Math. Model., 32(4), pp. 610-616 (2008).

35. Zhang, T., Zhao, Q., and Wu, W. "Bi-level programming model of container port game in the container transport supernetwork", J. Appl. Math. Comput., 31(1-2), pp. 13-32 (2009).

36. Gelareh, S., Nickel, S., and Pisinger, D. "Liner shipping hub network design in a competitive environment", Transp. Res. Part E Logist. Transp. Rev., 46(6), pp. 991-1004 (2010).

37. Kücükaydin, H., Aras, N., and Kuban Altinel, I. "Competitive facility location problem with attractiveness adjustment of the follower: a bilevel programming model and its solution", Eur. J. Oper. Res., 208(3), pp. 206-220 (2011).

38. Naimi Sadigh, A., Mozafari, M., and Karimi, B. "Manufacturer-retailer supply chain coordination: a bi-level programming approach", Adv. Eng. Softw., 45(1), pp. 144-152 (2012).

39. Kristianto, Y., Helo, P., and Jiao, R.J. "Mass customization design of engineer-to-order products using benders' decomposition and bi-level stochastic programming", J. Intell. Manuf., 24(5), pp. 961-975 (2013).

40. Rezapour, S. and Zanjirani Farahani, R. "Supply chain network design under oligopolistic price and service level competition with foresight", Comput. Ind. Eng., 72, pp. 129-142 (2014).

41. Rezapour, S., Farahani, R.Z., Dullaert, W., et al. "Designing a new supply chain for competition against an existing supply chain", Transp. Res. Part E Logist. Transp. Rev., 67, pp. 124-140 (2014).

42. Rezapour, S., Farahani, R.Z., Fahimnia, B., et al. "Competitive closed-loop supply chain network design with price-dependent demands", J. Clean. Prod., 93, pp. 251-272 (2015). 
43. Rashidi, E., Parsafard, M., Medal, H., et al. "Optimal traffic calming: a mixed-integer bi-level programming model for locating sidewalks and crosswalks in a multimodal transportation network to maximize pedestrians' safety and network usability", Transp. Res. Part E Logist. Transp. Rev., 91, pp. 33-50 (2016).

44. Han, J., Zhang, G., Hu, Y., et al. "A solution to bi/trilevel programming problems using particle swarm optimization", Inf. Sci., 370, pp. 519-537 (2016).

45. Saranwong, S. and Likasiri, C. "Bi-level programming model for solving distribution center problem: a case study in northern Thailand's sugarcane management", Comput. Ind. Eng., 103, pp. 26-39 (2017).

46. Shamekhi Amiri, A., Torabi, A., and Ghodsi, R. "An iterative approach for a bi-level competitive supply chain network design problem under foresight competition and variable coverage", Transp. Res. Part E Logist. Transp. Rev., 109, pp. 99-114 (2018).

47. Ghazanfari, M. and Murtagh, B.A. "A multi-objective hierarchical production planning model under stochastic demand", Sci. Irancia, 9(3), pp. 203-214 (2002).

48. Mula, J., Poler, R., Garcia-Sabater, J.P., et al. "Models for production planning under uncertainty: a review", Int. J. Prod. Econ., 103(1), pp. 271-285 (2006).

49. Leung, S.C.H. and Ng, W. "A goal programming model for production planning of perishable products with postponement", Comput. Ind. Eng., 53(3), pp. 531541 (2007).

50. Leung, S.C.H. and Chan, S.S.W. "A goal programming model for aggregate production planning with resource utilization constraint", Comput. Ind. Eng., 56(3), pp. 1053-1064 (2009).

51. Mirzapour Al-E-Hashem, S.M.J., Malekly, H., and Aryanezhad, M.B. "A multi-objective robust optimization model for multi-product multi-site aggregate production planning in a supply chain under uncertainty", Int. J. Prod. Econ., 134(1), pp. 28-42 (2011).

52. Zhang, G., Shang, J., and Li, W. "Collaborative production planning of supply chain under price and demand uncertainty", Eur. J. Oper. Res., 215(3), pp. 590-603 (2011).

53. Ghasemi Yaghin, R., Torabi, S.A., and Fatemi Ghomi, S.M.T. "Integrated markdown pricing and aggregate production planning in a two echelon supply chain: a hybrid fuzzy multiple objective approach", Appl. Math. Model., 36(12), pp. 6011-6030 (2012).

54. Ramezanian, R., Rahmani, D., and Barzinpour, F. "An aggregate production planning model for two phase production systems: solving with genetic algorithm and tabu search", Expert Syst. Appl., 39(1), pp. 1256-1263 (2012).

55. Awudu, I. and Zhang, J. "Stochastic production planning for a biofuel supply chain under demand and price uncertainties", Appl. Energy, 103, pp. 189-196 (2013).
56. Rahmani, D., Yousefli, A., and Ramezanian, R. "A new robust fuzzy approach for aggregate production planning", Sci. Iran. Trans. E, Ind. Eng., 21(6), p. 2307 (2014).

57. Da Silva, A.F. and Marins, F.A.S. "A fuzzy goal programming model for solving aggregate productionplanning problems under uncertainty: a case study in a Brazilian sugar mill", Energy Econ., 45, pp. 196-204 (2014).

58. Chakrabortty, R.K., Hasin, M.A.A., Sarker, R.A., et al. "A possibilistic environment based particle swarm optimization for aggregate production planning", Comput. Ind. Eng., 88, pp. 366-377 (2015).

59. Jabbarzadeh, A., Fahimnia, B., and Sheu, J.-B. "An enhanced robustness approach for managing supply and demand uncertainties", Int. J. Prod. Econ., 183, pp. 620-631 (2015).

60. Ramyar, M., Mehdizadeh, E., and Hadji Molana, M. "Optimizing reliability and cost of system for aggregate production planning in supply chain", Sci. Iran., 24(6), pp. 3394-3408 (2017).

61. Entezaminia, A., Heidari, M., and Rahmani, D. "Robust aggregate production planning in a green supply chain under uncertainty considering reverse logistics: a case study", Int. J. Adv. Manuf. Technol., 90(5-8), pp. 1507-1528 (2017).

62. Mokhtari, H. and Hasani, A. "A multi-objective model for cleaner production-transportation planning in manufacturing plants via fuzzy goal programming", J. Manuf. Syst., 44, pp. 230-242 (2017).

63. Hahn, G.J. and Brandenburg, M. "A sustainable aggregate production planning model for the chemical process industry", Comput. Oper. Res., 94, pp. 154168 (2018).

64. Leung, S.C.H., Tsang, S.O.S., Ng, W.L., et al. "A robust optimization model for multi-site production planning problem in an uncertain environment", Eur. J. Oper. Res., 181(1), pp. 224-238 (2007).

65. Gorissen, B.L., Yanıkoğlu, İ., and Hertog, D. "A practical guide to robust optimization", Omega, 53, pp. 124-137 (2015).

66. Zhen, J., Hertog, D., and Sim, M. "Adjustable robust optimization via Fourier-Motzkin elimination", Oper. Res., 66(4), pp. 1086-1100 (2018).

67. Bertsimas, D., Gupta, V., and Kallus, N. "Data-driven robust optimization", Math. Program., 167(2), pp. 235-292 (2018).

68. Pishvaee, M.S., Rabbani, M., and Torabi, S.A. "A robust optimization approach to closed-loop supply chain network design under uncertainty", Appl. Math. Model., 35(2), pp. 637-649 (2011).

69. Gabrel, V., Murat, C., and Thiele, A. "Recent advances in robust optimization: an overview", Eur. J. Oper. Res., 235(3), pp. 471-483 (2014). 
70. Beyer, H.-G. and Sendhoff, B. "Robust optimization-a comprehensive survey", Comput. Methods Appl. Mech. Eng., 196(33-34), pp. 3190-3218 (2007).

71. Bertsimas, D., Brown, D.B., and Caramanis, C. "Theory and applications of robust optimization", SIAM Rev., 53(3), pp. 464-501 (2011).

72. Vidal, C.J. and Goetschalckx, M. "A global supply chain model with transfer pricing and transportation cost allocation", Eur. J. Oper. Res., 129(1), pp. 134158 (2001).

73. Benders, J.F. "Partitioning procedures for solving mixed-variables programming problems", Numer. Math., 4(1), pp. 238-252 (1962).

74. MacRae, C.A.G., Ernst, A.T., and Ozlen, M. "A benders decomposition approach to transmission expansion planning considering energy storage", Energy, 112, pp. 795-803 (2016).

75. Pishvaee, M.S., Razmi, J., and Torabi, S.A. "An accelerated benders decomposition algorithm for sustainable supply chain network design under uncertainty: a case study of medical needle and syringe supply chain", Transp. Res. Part E Logist. Transp. Rev., 67, pp. 14-38 (2014).

76. Bagger, N.-C.F., S $\phi$ rensen, M., and Stidsen, T.R. "Benders' decomposition for curriculum-based course timetabling", Comput. Oper. Res., 91, pp. 178-189 (2017).

\section{Biographies}

Adel Aazami received his BSc degree in Industrial Engineering from University of Tehran in 2014 and his MSc degree in Industrial Engineering from Iran University of Science and Technology in 2016, Tehran, Iran, where he is currently a $\mathrm{PhD}$ student in the same major. His research interests include supply chain network design, competitive supply chain, aggregate production planning, production-distribution planning, perishable products, uncertain programming, and Benders decomposition algorithm. He has published 2 papers in related fields in some international journals and 5 papers in research indexed journals as well as more than 10 papers in some international conferences.

Mohammad Saidi-Mehrabad is a Professor in the Department of Industrial Engineering at Iran University of Science and Technology. He received his BSc degree in Mechanical Engineering from Oklahoma State University in 1983 and his MSc and PhD degrees in Industrial Engineering from University of Arkansas and West Virginia University in 1992. His major research interests are in cellular manufacturing, supply chain, and production planning as well as every optimization problem. He has published some books and a large number of papers in high-impact international journals and many papers in research indexed journals and international conferences. 